\title{
Клинические рекомендации Европейского респираторного общества по оценке кашля
}

Пуболикуется по Morice A.H., Fontana G.A., Belvisi M.G. et al. ERS guidelines on the assessment of cough. Eur. Respir. J. 2007; 29: 1256-1276

\author{
A.H.Morice, G.A.Fontana, M.G.Belvisi, S.S.Birring, K.F.Chung, P.V.Dicpinigaitis, J.A.Kastelik, L.P.McGarvey, \\ J.A.Smith, M.Tatar, J.Widdicombe \\ ERS guidelines on the assessment of cough
}

Кашель является наиболее частым поводом обращения за медицинской помощью [1, 2]. Острый кашель - самый частый и выраженный симптом обычной простуды, которая является наиболее распространенным заболеванием. В США ежегодные прямые и непрямые расходы на лечение простуды составляют 40 млрд долл. [3]. Хронический кашель как единственный симптом насчитывает 10-38\% всех обращений к специалистам по респираторной медицине [4, 5]. Недавно Европейское респираторное общество (ERS) опубликовало клинические рекомендации по ведению кашля [6]. Целью этого документа, как и рекомендаций, разработанных Американским колледжем торакальных врачей, было создание консенсуса по диагностике и лечению кашля как у взрослых, так и у детей [7]. Однако точной клинической и научной оценке кашля уделялось недостаточное внимание. В 2004 г. по решению ERS была сформирована рабочая группа для написания клинических рекомендаций по оценке кашля. Основной целью этой работы стало создание практического документа для исследователей, клиницистов, фармацевтов и организаторов здравоохранения. Он должен содержать следующие разделы: 1) безопасные стандартизованные методы кашлевых ингаляционных провокационных тестов; 2) надежные, воспроизводимые и применимые в клинической практике методы регистрации и анализа кашля; 3) клиническая оценка качества жизни в связи с кашлем; 4) эксперименты на животных для оценки новых методов лечения кашля; 5) направления дальнейших исследований. Ожидается, что такой документ поможет улучшить качество помощи пациентам, повысить качество исследований кашля и разработать новые эффективные методы лечения.

\section{Необходимость рекомендаций по оценке кашля}

Помимо отсутствия достаточного объема литературы потребность в подобном документе была обусловлена 4 основными факторами.

1. С середины 80-х гг. прошлого века резко увеличилось количество публикаций по различным аспектам кашля у человека и в экспериментах на животных. В базе данных PudMed поиск по слову "cough" за период с 1966 по 2005 гг. дал 22744 ис- точника - больше, чем для других респираторных симптомов, включая одышку и хрипы. Прогрессивный рост числа публикаций за эти 4 десятилетия представлен в табл. 1. География публикаций охватывает 5 континентов, что подтверждает актуальность клинической проблемы кашля.

2. Распространенность кашля чрезвычайно высока, и обследование больного будет неполным без оценки других связанных с кашлем клинических проблем. С этой целью разработана целая серия специфичных для кашля вопросников по качеству жизни, но необходимо выработать соглашение по их интерпретации и клиническому применению [8, 9]. Быстро развивается производство новых приборов для объективной регистрации и анализа кашля, которые требуют рекомендаций по клиническим и фармакологическим аспектам их применения.

3. Установлено значение кашлевых ингаляционных провокационных тестов как исследовательских методов у человека и на моделях животных [10, 11]. В существующей литературе описаны различные провокационные методы с широким выбором веществ, провоцирующих кашель, способов их доставки и конечных показателей. Требуется стандартизировать методики кашлевой провокации, т. к. необходимо сравнивать результаты, полученные в разных лабораториях. Чтобы получить разрешения этических комитетов на дальнейшие исследования, следует стандартизовать метод безопасной ингаляционной провокации кашля.

4. Обычно специфическая терапия, направленная на ликвидацию причины кашля, дает хороший

Таблища 1

Количество публикаций в базе данных PubMed, найденных по ключевому слову "соияh", за период 1966-2005 г2.

\begin{tabular}{|l|c|}
\hline Период, гг. & Кол-во публикаций \\
\hline $1966-1975$ & 2262 \\
\hline $1976-1985$ & 2968 \\
\hline $1986-1995$ & 6564 \\
\hline $1996-2005$ & 10950 \\
\hline
\end{tabular}


результат, но при этом отсутствуют эффективные неспецифические способы лечения. Они крайне необходимы пациентам с идиопатическим кашлем, с кашлем на фоне легочного фиброза и рака легкого и при неэффективности лечения по поводу бронхиальной астмы (БА) и хронической обструктивной болезни легких (ХОБЛ). Разработка новых лекарств затруднена, поскольку нет единого мнения о том, какая модель экспериментов на животных является наиболее оптимальной. Важным шагом к созданию эффективных способов лечения кашля должны стать рекомендации по надежным и информативным испытаниям новых видов лечения на животных.

\section{Методы}

Рабочая группа состояла из приглашенных экспертов в области оценки и лечения кашля. Ее 1-е совещание состоялась в 2004 г. на ежегодном конгрессе ERS в Глазго (Великобритания), последующие в 2005 г. в Амстердаме (Нидерланды) и в том же году на ежегодном конгрессе ERS в Копенгагене (Дания). На 1-й встрече участники пришли к соглашению, что клинические рекомендации по возможности должны опираться на высокодоказательные оригинальные публикации и обзоры. Однако было очевидно, что данные во многих областях, таких как исследования кашлевого рефлекса, использование специфических для кашля вопросников по качеству жизни и новых записывающих кашель устройств, недостаточны (например, представлены в виде резюме), и, следовательно, возможности создания доказательных рекомендаций были ограниченны. В этих случаях рекомендации основывались на мнениях экспертов рабочей группы. Между отдельными экспертами или небольшими группами были распределены специфические темы, по котором на основании обзора литературы были написали статьи, обсуждавшиеся на следующих совещаниях. Рекомендации по таким вопросам разрабатывались по результатам обсуждений.

\section{Структура документа}

Разделы данного документа посвящены отдельным аспектам оценки кашля, а именно кашлевой провокации у человека, регистрации кашля, оценке влияния кашля на качество жизни, моделям кашля на животных, дизайну и проведению клинических испытаний противокашлевых препаратов. Каждый раздел начинается с резюме существующей литературы, завершающегося направлениями для дальнейших исследований, после чего следуют клинические рекомендации рабочей группы.

\section{Определение кашля}

Несмотря на то, что кашель описан во всех учебниках, в большинстве научных статей нет его четкого определения [12]. В данных клинических рекомендациях используются следующие 2 формулировки $[13,14]$ :

1. Кашель - это 3-фазный экспульсивный двигательный акт, который характеризуется инспираторным усилием (инспираторная фаза), после чего следует форсированное экспираторное усилие при закрытом надгортаннике (фаза компрессии) и затем быстрый выдох при открытом надгортаннике (фаза выталкивания, или экспульсивная фаза) [13].

2. Кашель - форсированный экспульсивный маневр, обычно при закрытом надгортаннике, который сопровождается характерными звуками [14].

Несмотря на некоторое сходство этих определений, между ними существуют значительные различия, касающиеся паттерна дыхания при кашле. В частности, начальная инспираторная фаза, упоминаемая в 1-м случае, является одной из множества черт, отличающих кашель от другого защитного рефлекса в дыхательных путях - выдоха [12].

Более того, ни в одном из определений не рассматривается частое клиническое явление, при котором за начальным кашлевым толчком следует серия кашлевых усилий. Пациенты нередко называют его приступом кашля. Исследователь может различать отдельные кашлевые толчки или длительный непрерывный эпизод кашля. Это имеет очевидное значение для точной регистрации частоты кашля. И для врача, и для больного важным было бы определение, отражающее ощущение, связанное с необходимостью покашлять, интенсивность кашля и его влияние на состояние здоровья.

\section{Рекомендации}

1. Во всех фундаментальных научных работах кашель характеризуется как 3-фазный двигательный акт. Однако в клинических исследованиях на основании записи акустических сигналов кашель расценивается как форсированный экспульсивный маневр при закрытом надгортаннике, сопровождаемый характерными звуками.

2. Во всех научных статьях должно содержаться четкое определение кашля.

\section{Ингаляционный провокационный кашлевой тест с капсаицином и лимонной кислотой}

\section{Методика}

Ингаляционная провокация кашля позволяет измерять чувствительность кашлевого рефлекса и оценивать эффективность противокашлевых препаратов. В целом ингаляционные кашлевые провокационные тесты разделяют на те, в которых используются кислотные и некислотные индукторы кашля. Некислотный индуктор кашля капсаицин, который чаще всего применяется в экспериментах с участием человека, впервые описан в 1984 г. [15]. Наиболее широко используемыми кислотными индукторами кашля являются лимонная и тартаровая кислоты [16]. Провокация кашля при ингаляции раствора лимонной кислоты описана в середине 50-х гг. XX в. [16, 17]. Способность лимонной кислоты и капсаицина вызывать кашель зависит от дозы и обладает воспроизводимостью [16, 18].

К сожалению, из-за недостатка стандартизации оборудования, приготовления растворов, способов 
их доставки, параметров небулайзера, инспираторного потока и дозы аэрозоля на 1 вдох при проведении кашлевых провокационных тестов сегодня невозможно сравнивать данные о чувствительности кашлевого рефлекса, имеющиеся в литературе. В этом разделе предлагаются рекомендации по стандартизации ингаляционных кашлевых провокационных тестов с использованием как кислотных, так и некислотных индукторов кашля.

\section{Приготовление и хранение растворов капсаицина}

Капсаицин (30,5 мг) растворяется в 1 мл чистого этанола и 1 мл полиоксиэтилена сорбитана (Tween 80) и затем разводится 8 мл физиологического раствора для получения 0,01 М раствора, который можно хранить (сток-раствор) [19, 20]. Без детергента Tween 80 раствор получается мутным. Далее он разбавляется физиологическим раствором для получения серийных разведений от 0,49 до 1000 мкмоль. Для здоровых добровольцев минимальной будет концентрация раствора 0,98 М, т. к., по опыту авторов, при таком условии кашель возникает редко.

Остается неясным, как часто надо готовить свежий сток-раствор. В недавно выполненном исследовании авторы пришли к выводу, что раствор капсаицина (концентрация $\geq 4$ мкмоль) остается стабильным в течение 1 года при хранении в темном месте при температуре $+4{ }^{\circ} \mathrm{C}[21]$.

\section{Приготовление раствора лимонной кислоты}

Серийные разведения 3-молярного сток-раствора лимонной кислоты в стерильном 0,9\%-ном физиологическом растворе выполняются для получения серийных удваивающихся концентраций от 1,95 до 3000 ммоль [22-24]. Для здоровых добровольцев минимальная концентрация составляет 7,8 ммоль. Как для капсаицина, так и для лимонной кислоты свежие разведения готовятся из сток-раствора непосредственно в день исследования. Сток-растворы хранят при температуре около $-10{ }^{\circ} \mathrm{C}$ для капсаицина и $4{ }^{\circ} \mathrm{C}$ для лимонной кислоты. Рекомендуется использовать свежий раствор для каждого провокационного теста.

Для соблюдения "слепого" дизайна участники исследования ингалируют капсаицин и лимонную кислоту в серийных удваивающихся концентрациях и $0,9 \%$-ный физиологический раствор в рандомизированном порядке [22-24].

\section{Назначение капсаицина и лимонной кислоты}

Основными способами кашлевой провокации капсаицином и лимонной кислотой являются метод одиночного вдоха и дозозависимый метод [25]. В последнем случае используется 1 концентрация капсаицина или лимонной кислоты. Провокация по дозозависимому методу может представлять собой либо 1-кратные вдыхания каждой из возрастающих концентраций капсаицина или лимонной кислоты на уровне жизненной емкости легких, либо ингаляцию каждой из возрастающих концентраций при спокойном дыхании в течение фиксированного времени (обычно - 15-60 с).
Большинство исследователей предпочитают метод одиночного вдоха из-за точности и воспроизводимости дозы и простоты определения кашлевого ответа. При продолжительных ингаляциях капсаицина и лимонной кислоты различия в частоте дыхания и дыхательном объеме у разных пациентов, вероятно, могут обусловливать разные количества аэрозоля, получаемые каждым пациентом, а также одним и тем же пациентом при разных концентрациях. Это следует особо учитывать при назначении концентраций, индуцирующих сильный кашель и тем самым препятствующих вдыханию больным больших объемов аэрозоля в течение фиксированного времени ингаляции. Тем не менее недавно опубликованное сравнение провокационного кашлевого теста с капсаицином при спокойном дыхании и использовании дозиметрии продемонстрировало, что оба метода воспроизводимы и дают сходные результаты [26].

\section{Повышение воспроизводимости кашлевых провокационных тестов с капсаицином и лимонной кислотой}

\section{Скорость инспираторного потока}

Скорость инспираторного потока влияет на поступление аэрозоля в дыхательные пути. Колебания скорости инспираторного потока, как было показано, влияют на результаты капсаицинового [27] теста и теста с лимонной кислотой [28]. Так, более низкая скорость инспираторного потока (50 л/мин по сравнению с 150 л/мин) приводит к более выраженной кашлевой реакции на лимонную кислоту [28].

Таким образом, необходимо вдыхать аэрозоль с постоянной скоростью. Если инспираторный поток не контролируется, разные люди получают разное количество провоцирующего вещества и даже у одного пациента дозы, ингалируемые в течение разных дыхательных циклов, будут отличаться. Такие колебания дозы аэрозоля, доставляемой в дыхательные пути, могут влиять на результаты исследования, особенно когда важна воспроизводимость теста (например, в фармакологических исследованиях с оценкой чувствительности кашлевого рефлекса до и после терапии и в эпидемиологических исследованиях, в которых сравниваются различные популяции больных).

Для контроля скорости инспираторного потока рекомендуется использовать компрессорный небулайзер (модель 646, DeVilbiss, Health Care Inc., США) с дозиметром (KoKo DigiDoser; nSpire health Inc., США) и клапаном, регулирующим скорость вдоха. Этот клапан ограничивает скорость инспираторного потока до 0,5 л/с даже при избыточном инспираторном усилии и, следовательно, гарантирует постоянное и воспроизводимое инспираторное усилие в каждом дыхательном цикле. Таким образом, все пациенты, получив указания делать вдох с достаточным усилием, каждый раз ингалируют аэрозоль с одинаковой инспираторной скоростью.

\section{Характеристики небулайзера}

Значительные колебания в количестве аэрозоля, доставляемом в дыхательные пути при каждом вдохе, 
могут возникать при использовании стандартного небулайзера даже у тех пациентов, которые стараются поддерживать постоянную скорость вдоха. Другим важным фактором распределения аэрозоля являются технические характеристики самого небулайзера. Например, в модели 646 DeVilbiss мундштук и распылитель съемные. Когда их отсоединяют от небулайзера для промывания и затем вновь надевают, расстояние между мундштуком и распылителем, с одной стороны, и источником сжатого воздуха и выпускным отверстием - с другой, может меняться. Эти колебания расстояния, хотя и минимальные, меняют выходные характеристики небулайзера. Следовательно, для улучшения воспроизводимости следует модифицировать небулайзер: во-первых, следует добавить клапан, регулирующий скорость инспираторного потока, а во-вторых, мундштук и распылитель должны быть зафиксированы неподвижно. После такого усовершенствования необходимо определить точную скорость воздушной струи на выходе из небулайзера (в мл/мин), после чего, зная время доставки аэрозоля в дыхательные пути, можно рассчитывать дозу аэрозоля при каждом вдохе. Например, при скорости воздушной струи на выходе из небулайзера 1,007 мл/мин и времени доставки 1,2 с доза аэрозоля при каждом вдохе составит 0,02 мл.

Учитывая потенциальную вариативность выходных параметров небулайзера, важно использовать в клинических исследованиях модифицированные аппараты, а при серийных исследованиях кашля у одного и того же пациента либо при сравнении популяций - один и тот же небулайзер либо оборудование с одинаковыми характеристиками. Поскольку в реальности в исследованиях по-прежнему будут использоваться разные типы оборудования, рекомендуется стандартизировать провокационные кашлевые тесты путем контроля дозы аэрозоля, ингалируемой за один дыхательный цикл.

\section{Ингаляции плацебо}

Для проведения кашлевых провокационных тестов в "слепом" дизайне между возрастающими концентрациями капсаицина или лимонной кислоты пациентам рандомизированно ингалируют физиологический раствор (плацебо) [25, 29]. Такая тактика снижает вероятность влияния самого больного на результат теста в случаях, когда он ждет кашлевого эффекта от возрастающих концентраций провоцирующего вещества.

\section{Инструкции для пациента}

Перед выполнением провокационного теста пациенту объясняют, что он не должен подавлять кашель и разговаривать сразу после ингаляции провоцирующего вещества, т. к. это тоже может уменьшать выраженность кашля. Рекомендуется, например, такая инструкция: "Вы можете кашлять, когда появляется такое желание, и можете кашлять столько, сколько вам нужно". Не следует говорить испытуемому, что исследование будет прекращено при появлении кашля определенной интенсивности (см. раздел
"Интерпретация результатов кашлевого провокационного теста") [11].

\section{Определение кашлевого ответа в провокационном тесте}

При проведении провокационного теста методом одиночного вдоха капсаицина или лимонной кислоты кашлевой ответ на ингаляцию каждой дозы будет немедленным и кратковременным, поэтому учитывают только кашлевые толчки, возникающие в течение 15 с после ингаляции капсаицина или лимонной кислоты [10, 25, 30, 31]. Кашель, появляющийся позже, не может быть вызван капсаицином или лимонной кислотой.

\section{Интерпретация результатов провокационного теста}

В каждом тесте регистрируют концентрацию капсаицина или лимонной кислоты, вызывающую 2 (С2) или 5 (С5) кашлевых толчков. Это 1-я концентрация, которая провоцирует $\geq 2$ или $\geq 5$ кашлевых толчков соответственно; ее можно установить путем интерполяции по кривой логарифмов концентрацияответ. В большинстве случаев разница в результатах, получаемых этими 2 способами, очень мала [32]. Интерполированные концентрации близки к реальным С2 и С5, но не имеют преимуществ перед установлением концентрации непосредственно при ингаляции. Мнения исследователей расходятся в том, какой показатель расценивать как основной результат исследования - С2 или С5. В опубликованных работах часто приводят обе величины, но нередко присутствует только С5. Доказано, что С5 может иметь большее клиническое значение [11], однако другие исследования продемонстрировали, что С2 более воспроизводима [29]. До появления новых данных рекомендуется измерять обе концентрации.

Возможной проблемой при серийных провокационных кашлевых тестах могут быть некоторые неожиданные эффекты [11]. У пациентов, впервые участвующих в таком исследовании, кашель может быть слишком сильным - такой феномен при использовании лимонной кислоты описан в 50-х гг. XX в. [16]. В такой ситуации могут потребоваться предварительные разъяснения либо можно использовать С5, поскольку ее легче достичь.

В некоторых случаях у лиц с относительно высоким кашлевым порогом нельзя достичь С5, несмотря на максимальные концентрации индукторов кашля. Ингаляции высоких доз капсаицина препятствует сильное ощущение жжения в верхних дыхательных путях, а лимонная кислота может провоцировать ощущение сдавления или дискомфорт в горле [18]. Авторы рекомендуют исключать таких пациентов из сравнительных клинических исследований, поскольку истинную С5 у них нельзя получить, а в популяционных исследованиях лучше использовать С2.

\section{Значение оценки кашлевой чувствительности к капсаицину и лимонной кислоте}

Изолированные измерения кашлевой чувствительности к капсаицину (С2 или С5) не имеют самостоятельного значения из-за большой вариабельности 


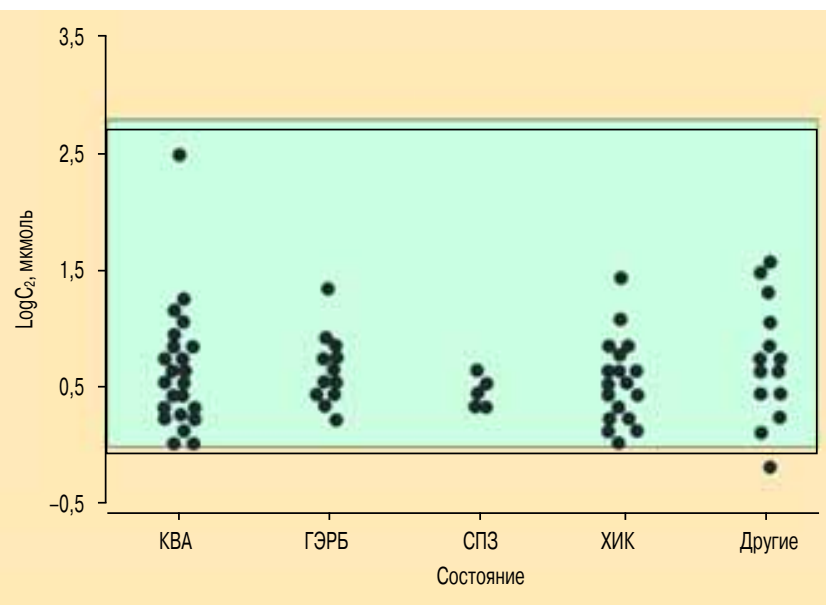

Рис. 1. Чувствительность кашлевого рефлекса к капсаицину и лимонной кислоте у больных с хроническим кашлем (зеленым цветом выделена область нормальных величин, вычисленная по результатам обследования 134 здоровых добровольцев). $\mathrm{C}_{2}$ - концентрация капсаицина, вызывающая 2 кашлевых толчка; КВА - кашлевой вариант астмы; ГЭРБ - гастро-эзофагеальная рефлюксная болезнь, СПЗ - синдром постназального затекания (ринит), ХИК - хронический идиопатический кашель; другие - ХОБЛ, саркоидоз, криптогенный фиброзирующий альвеолит, бронхоэктазы. Переработано из [33]

чувствительности кашлевого рефлекса в нормальной популяции (рис. 1), в отличие от оценки бронхиальной гиперреактивности, когда концентрация бронхоконстрикторного вещества, вызывающая 20\%-ное падение объема форсированного выдоха за 1-ю с $\left(\mathrm{OФB_{1 } )}\right.$, находится за пределами нормы и коррелирует с патофизиологическими изменениями [34]. Тем не менее, поскольку измерение чувствительности кашлевого рефлекса к капсаицину и лимонной кислоте высоковоспроизводимо, если выполняется по точной методике $[11,16-18,25]$, эти исследования важны в фармакологических (серийные измерения) и эпидемиологических исследованиях (сравнение разных популяций).

\section{Обработка оборудования}

Для каждого пациента оборудование следует стерилизовать по правилам, принятым в данном учреждении. Так, например, протокол, используемый авторами данных рекомендаций, предполагает стерилизацию в течение 15 мин в растворе Pera®Safe* (Antec International Ltd, Великобритания), после чего оборудование тщательно промывается горячей водой и высушивается на воздухе.

\section{Тахифилаксия и воспроизводимость}

При повторных кашлевых провокациях в течение короткого времени может возникать тахифилаксия. Действительно, если ингаляция длится > 1 мин, то при использовании капсаицина частота кашля уменьшается на 1/3, а при применении лимонной кислоты он полностью прекращается. Повторные кашлевые провокации методом одиночного вдоха с 10-минутным интервалом также приводят к подобной тахифилаксии [35]. Рекомендуется делать перерыв на 1 ч, а лучше на 2 ч между повторными кашлевыми провокациями. Многие исследователи сообщают о высокой долговременной воспроизводимости кашлевых провокационных тестов с капсаицином и лимонной кислотой по дозозависимому методу и методу 1 дозы как при одиночном вдохе [11, 16, 17, 26, 29, 33, 36-41], так и при фиксированном времени ингаляции [15-18, 26, 35, 42, 43].

В 2 исследованиях подтверждена воспроизводимость провокационного кашлевого теста с капсаицином через 3 мес. [44] и > 6 мес. [11]. В последнем исследовании показана хорошая воспроизводимость теста с капсаицином у 40 здоровых добровольцев через 16,7 мес. в среднем. В другой работе продемонстрирована хорошая воспроизводимость кашлевого провокационного теста с лимонной кислотой [45].

\section{Безопасность}

В недавно опубликованном обзоре 20-летнего клинического опыта применения теста с капсаицином не выявлено ни одного серьезного побочного эффекта, связанного с этим исследованием у человека [46]. В нем проанализированы 122 исследования, опубликованные после 1984 г., с участием 4833 пациентов, в т. ч. здоровых взрослых добровольцев и детей, а также больных с патологическим кашлем, БА, ХОБЛ, гипертензией, гастро-эзофагеальной рефлюксной болезнью (ГЭРБ), интерстициальными заболеваниями легких, острыми инфекциями верхних дыхательных путей и повреждением шейного отдела позвоночника, трансплантацией комплекса сердцелегкие и муковисцидозом [46]. Нежелательные эффекты были представлены в основном преходящим раздражением горла у небольшого числа пациентов.

Безопасность провокационного теста с лимонной кислотой описана в 50-х гг. ХХ в. [16, 17]. Однако ингаляция лимонной кислоты может привести к небольшому снижению ОФВ $1(<5 \%)$, которое вряд ли имеет клиническое значение [10]. Капсаицин также не вызывал клинически значимой бронхоконстрикции ни у здоровых добровольцев, ни у астматиков $[15,47]$.

Тем не менее при выполнении кашлевых провокационных тестов следует предусмотреть возможность проведения бронхолитической терапии.

У женщин - как здоровых, так и больных с хроническим кашлем - повышена чувствительность кашлевого рефлекса на капсаицин [48, 49], лимонную и тартаровую кислоты [22, 50, 51].

Кашлевая реакция на плацебо характеризуется нелинейным повышением супрессии кашля, которая становится наиболее выраженной через 4 ч [40]. Кроме того, существует мнение, что женщины кашляют чаще и быстрее адаптируются к кашлю, чем мужчины.

Контактную информацию об этих исследователях можно найти на сайте международного общества по исследованию кашля (International Society for the Study of Cough) [52].

* $\quad$ Pera $\AA S a f e-$ водный раствор мягкого мыла. - Примеч. nер. 


\section{Дальнейшие исследования}

В настоящее время отсутствуют данные о кратковременной и долговременной воспроизводимости ингаляционного провокационного теста с лимонной кислотой, хотя такие исследования уже ведутся. Необходимо и дальше накапливать информацию о воспроизволимости всех кашлевых провокационных тестов.

\section{Рекомендации}

1. Методика выполнения ингаляционных провокационных кашлевых тестов должна быть стандартизована, что необходимо для единой интерпретации результатов и сопоставления данных, полученных в разных лабораториях.

2. Следует разработать универсальные должные величины кашлевых провокационных тестов на основании стандартизованной методики, приведенной в данном документе.

3. Для большинства экспериментальных протоколов рекомендуется дозозависимый метод одиночного вдоха с использованием дозиметра, ограничивающего воздушный поток.

4. Следует регистрировать как С2, так и С5 кашлевых толчков.

5. Результаты кашлевых провокационных тестов не имеют самостоятельного значения, т. к. значительно различаются у разных испытуемых, но достаточно ценны при оценке динамики чувствительности кашлевого рефлекса у отдельных пациентов.

\section{Кашель, вызванный ингаляцией водных растворов}

Для оценки кашля и других рефлекторных респираторных реакций с использованием аэрозолей водных растворов рекомендуется применять ультразвуковые небулайзеры, поскольку в литературе отсутствуют сообщения о возникновении подобных реакций при использовании обычных небулайзеров. Технические характеристики и принципы работы наиболее широко применяемых ультразвуковых небулайзеров рассматриваются в других работах [53, 54]. В целом ультразвуковые небулайзеры распыляют гораздо больше раствора в единицу объема воздуха, чем обычные [53]. Поскольку туссогенное влияние любого водного раствора обусловлено сниженной концентрацией аниона, особенно хлорида [55], любой раствор с низкой концентрацией анионов может использоваться в качестве индуктора кашля.

\section{Доставка аэрозоля}

Водный аэрозоль лучше поступает в дыхательные пути при спокойном дыхании. Во избежание повторного вдыхания одной и той же порции аэрозоля рекомендуется использовать 2-направленный клапан [55-56] либо располагать выходное отверстие проксимально по отношению к дыхательным путям пациента $[57,58]$. Чтобы скорость поступления аэрозоля в дыхательные пути была постоянной, аэрозоль должен содержаться в 1,5-2-литровой емкости [57].

\section{Дозирование аэрозоля}

Провокационные тесты с небулизированными водными растворами можно выполнять 2 методами 1 дозы и дозозависимым. В 1-м случае заранее устанавливается определенная выходная мощность небулайзера (обычно максимально возможная), и небулизированный раствор ингалируется в течение определенного времени (обычно 1 мин) [35, 59-62]. Дозозависимая провокация проводится с прогрессивно увеличивающейся интенсивностью ингаляции, что достигается ступенчатым повышением выходной мощности аппарата (рис. 2), причем каждая ступень соответствует определенной доле максимальной мощности $[55,57]$. При другом варианте того же метода можно при постоянной мощности небулайзера увеличивать провоцирующую силу ингалируемого раствора, используя растворы с прогрессивно снижающейся концентрацией анионов [61-63].

\section{Конечные показатели / чувствительность}

При провокационном тесте методом 1 дозы кашлевой ответ оценивается по частоте кашля [35, 59-62], которая, однако, может снижаться по мере адаптации к провоцирующему веществу [35]. При дозозависимом методе кашлевой провокации чувствительность кашлевого рефлекса оценивается по кашлевому порогу, т. е. по минимальной интенсивности провоцирующего фактора, способной вызывать хотя бы 1 кашлевой толчок в течение 2 дозозависимых провокаций с 30-минутным интервалом [56-58]. Надежность других конечных показателей, таких как С2 и С5, т. е. минимальной интенсивности провоцирующего фактора, способной вызывать как минимум 2 или 5 кашлевых толчков, при использовании водных аэрозолей не исследуется. Такие параметры, как скорость кашлевого экспираторного потока [57, 64] и сила, развиваемая экспираторными мышцами при

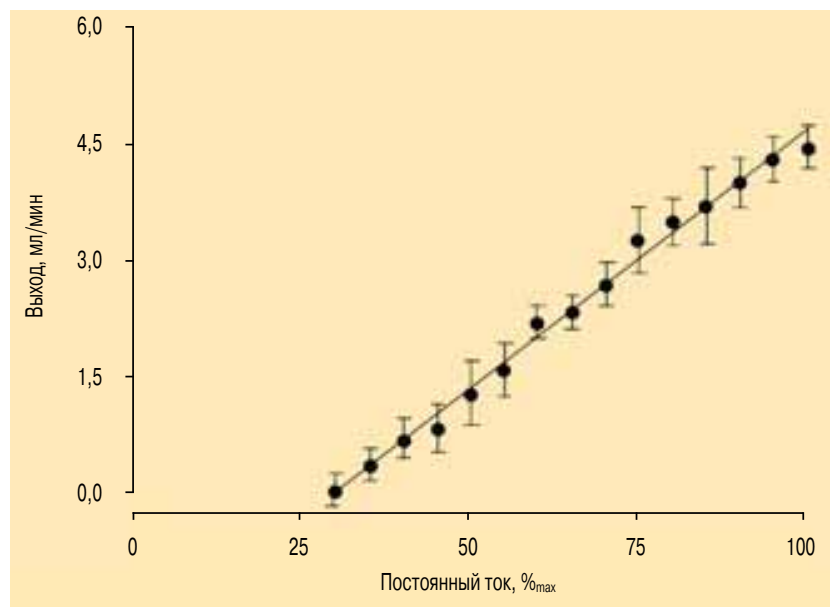

Рис. 2. Взаимосвязь между выходными параметрами ультразвукового небулайзера ( $y)$ и показателями постоянного тока $(x)$, проанализированными с применением регрессионного метода наименьших квадратов. Данные представлены как $M \pm S D$. Взаимосвязь оценивалась по линейной модели $(r=0,95 ; p<$ $0,001)$, средний выход небулайзера рассчитывался по следующему уравнению: $y=-1,90+0,66 x$. Разброс выхода (средние величины) обычно составляет $0,08-4,45$ мл/мин, т. е. $30-100 \%$ от максимального постоянного тока 
одиночном кашлевом усилии [56-58, 64], позволяют оценить выраженность моторного ответа.

\section{Воспроизводимость}

Воспроизводимость тестов чувствительности $[35,57$, 63-65] и интенсивности $[57,66]$ кашлевого рефлекса установлена в нескольких исследованиях в дозозависимых провокационных пробах с ингаляцией дистиллированной воды $[35,57,66]$ и других водных растворов $[63,65]$ через ультразвуковые небулайзеры.

\section{Безопасность}

Ультразвуковые небулайзеры, разумеется, не являются одноразовыми и достаточно дороги. Рекомендуется стерилизовать их после каждого использования, что существенное ограничивает применение аэрозолей, небулизированных ультразвуком, вне научных исследований. Более того, у пациентов, предрасположенных к бронхоспазму, гипотонические аэрозоли могут оказывать бронхоконстрикторное действие [55].

Вместе с тем кашлевые провокационные тесты с водными аэрозолями имеют ряд преимуществ. Интенсивность провоцирующего агента можно увеличивать постепенно, что позволяет достаточно точно определить кашлевой порог. Помимо этого, учитывая, что водные аэрозоли ингалируются при относительно спокойном дыхании, можно одновременно записывать несколько показателей паттерна дыхания и, таким образом, изучать вентиляционные приспособительные механизмы, активируемые стимуляцией рецепторного аппарата дыхательных путей.

\section{Направления дальнейших исследований}

Стимуляция чувствительных рецепторов аэрозолем может быть обусловлена как отсутствием в нем хлоридных ионов (что вызывает кашель), так и гипоосмолярностью (что вызывает бронхоконстрикцию у лиц, склонных к бронхоспазму). Остается неясным, какие из этих стимулов ответственны за соответствующие изменения паттерна дыхания. Практичность и воспроизводимость параметров, таких как С2 и С5, при оценке кашлевой чувствительности к водным аэрозолям также требуют дальнейших исследований.

\section{Рекомендации}

1. Аэрозольные водные растворы являются ценным экспериментальным средством для исследования кашля.

2. Кашлевой провокационный тест с ультразвуковым распылением дистиллированной воды ("туман") трудно стандартизировать, поскольку во многом он зависит от выходных характеристик небулайзера.

3. Следует помнить о потенциальных побочных эффектах, таких как бронхоконстрикция и передача инфекции.

\section{Мониторирование кашля}

С 50-х гг. ХХ в. исследователи пытаются объективизировать оценку кашля [67-69], т. е. измерить ка- шель количественно за единицу времени. Можно сделать звуковую запись кашля и вручную подсчитать число кашлевых эпизодов, но это трудоемкий процесс. В настоящее время отсутствуют стандартизованные методы и валидизированные непатентованные мониторинги, которые можно было бы использовать в клинической практике.

Объективный показатель кашля мог бы применяться в практической работе врача, клинических исследованиях и при оценке новых видов лечения. С его помощью можно было бы подтвердить наличие кашля, оценить его тяжесть и эффективность лечения. Его разработка представляет собой обширную область для исследований. Для автоматической идентификации и количественной оценки кашля разрабатываются различные системы, в которых используются последние технические достижения.

Цель данных клинических рекомендаций - предоставить информацию о необходимых качествах идеального прибора и методах мониторирования кашля как разработчикам, так и потенциальным пользователям кашлевых мониторов.

\section{Неамбулаторные методы записи кашля}

Самые первые системы для мониторирования кашля были стационарными. Для оценки кашля у госпитализированных больных или в рамках исследований в ночное время применяли магнитофоны с питанием от электросети с выносным микрофоном [67, 70].

\section{Амбулаторные методы записи кашля}

Наиболее часто применяются портативные системы, которые позволяют подсчитывать кашель в течение определенного периода (обычно 24 ч). Преимущества компьютеров и цифровой регистрации данных делают возможным цифровую запись звука. По-прежнему представляет трудность точное распознавание кашлевых звуков. Несколько групп исследователей применяли цифровые методы обработки звука, но с ограниченным успехом [71-74]. Таким образом, в большинстве систем по-прежнему ведется подсчет вручную, что является утомительным и ограничивает размер исследований.

$\mathrm{K}$ настоящему времени описано $>6$ различных систем, которые позволяют идентифицировать кашлевые звуки [72, 73, 75-79]. В одной из первых систем 24-часового мониторирования для количественной оценки кашля служило стационарное многоканальное записывающее устройство [75]. Кашель интерпретировался как одновременное появление кашлевых звуков в цифровом преобразовании и электромиографических сигналов от респираторных мышц. Сигналы анализировали визуально и подсчитывали вручную.

Другая система, в которой кашлевые звуки передавались с микрофона на домашний компьютер пациента, использовала телеметрию [77]. Кашлевые звуки в цифровом формате подсчитывали вручную, а также измеряли латентный период (промежуток времени между кашлевыми толчками), кашлевое усилие (интеграл спектра акустической мощности), 
интенсивность кашля (кашлевое усилие, поделенное на число кашлевых толчков) и его влажность.

В одной из систем кашель количественно оценивался по продолжительности во времени, т. е. по числу секунд, в течение которых продолжался хотя бы 1 кашлевой толчок [78, 80, 81]. Это применялось в большей степени для формулировки более полного определения кашля, а не для обычной фиксации кашлевых звуков, которые можно просто услышать.

С точки зрения автоматизации систем для распознавания кашля A.H.Morice и A.D.Walmsley [73] описали вероятностную нервную систему для дифференциации кашля от некашлевых звуков. С помощью цифрового устройства для аудиозаписи Sony Walkman (Sony, Малайзия) было показано, что эта система позволяет зарегистрировать столько же кашлевых звуков, что и ручной подсчет.

S.Birring et al. [82, 83] разработали кашлевой монитор Лейчестера, который диагностировал кашель у пациентов с хроническим сухим кашлем, используя статистическую модель, и характеризовал кашель количественно как отдельные эпизоды.

Посредством амбулаторной кардиореспираторной мониторинговой системы (LifeShirt, Vivometrics, США) со встроенным ненаправленным контактным микрофоном измеряли кашель у 8 больных ХОБЛ в лабораторных условиях; аппаратура производила автоматический подсчет на основании статистических параметров [79]. При сравнении этих данных с подсчетом кашля по видео- и аудиозаписям получена хорошая корреляция.

\section{Определение кашля}

Процесс кашля сопровождается характерными звуками [84], причина появления которых - быстрые изменения воздушного потока за счет сокращения мышц грудной клетки, живота, диафрагмы и гортани. В связи с этим существует множество возможностей для выявления кашля (табл. 2). Его диагностика зависит от мониторируемых сигналов. Наиболее часто применяется количественная оценка с использованием либо только звуков, либо звуков наряду с другим сигналом [75, 76, 79, 85].

Фазы типичного кашля приведены на рис. 3. Важно, чтобы любой прибор для мониторирования кашля имел четкие установки, что именно является кашлем, по каким сигналам и как проводится его количественная оценка.

Таблица 2

Сигналы и типы сенсоров для мониторирования кашля

\begin{tabular}{|l|l|}
\hline $\begin{array}{l}\text { Сигнал } \\
\text { Звук }\end{array}$ & \multicolumn{1}{c}{ Сенсор } \\
& \multicolumn{1}{c}{ Выносной микрофон } \\
& $\begin{array}{l}\text { Микрофон с воздушным проведением звука } \\
\text { Контактный микрофон }\end{array}$ \\
\hline Движения & $\begin{array}{l}\text { Электромиография } \\
\text { Акселерометрия } \\
\text { Индукционная плетизмография }\end{array}$ \\
\hline
\end{tabular}

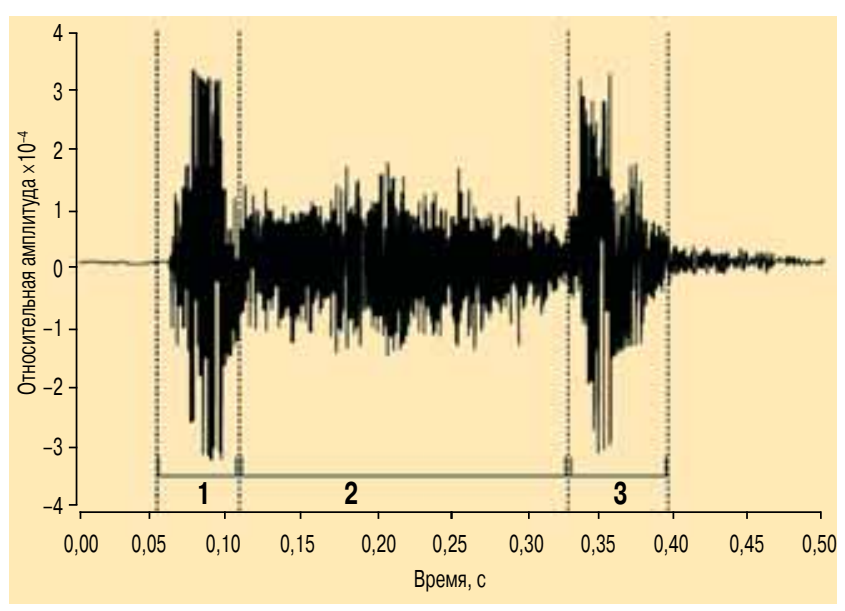

Рис. 3. Трехфазные кашлевые звуки (1 - "взрывная" фаза; 2 - промежуточная фаза; 3 - голосовая фаза)

\section{Количественная оценка кашля}

Одна из трудностей в выявлении и количественной оценке кашля - существование множества различных его паттернов. По анализу звуковых сигналов описано 3 основных паттерна (рис. 3-5) [84, 86, 87], но на самом деле их гораздо больше. Оценить кашель количественно можно разными способами. На рис. 6 показана короткая запись кашлевых звуков и 4 разных способа их количественного выражения:

1. Подсчет приступообразных кашлевых звуков ("взрывов"; рис. 6а) является интуитивным методом подсчета кашля.

2. Для определения длительности кашля в секундах (рис. 6б) измеряется время, в течение которого продолжается кашель - число секунд в течение каждого часа, соответствующих хотя бы 1 приступу.

3. Способ измерения кашлевых вдохов (рис. 6в) применяется в системе, которая непрерывно мониторирует дыхание и подсчитывает кашель как число дыханий, содержащих хотя бы 1 звук кашля.

4. Еще один способ - оценка приступов кашля (рис. 6 г), продолжительных кашлевых звуков с паузами $<2$ с.

Степень достоверности каждого из этих способов не определена, но важно указывать, какие единицы кашля используются. При большинстве состояний

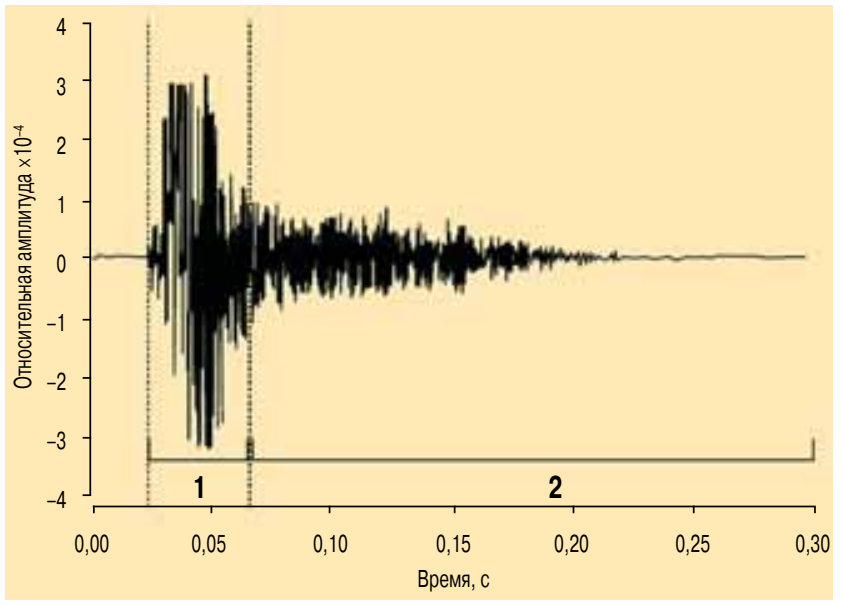

Рис. 4. Двухфазные кашлевые звуки (1 - "взрывная" фаза; 2 - промежуточная фаза) 


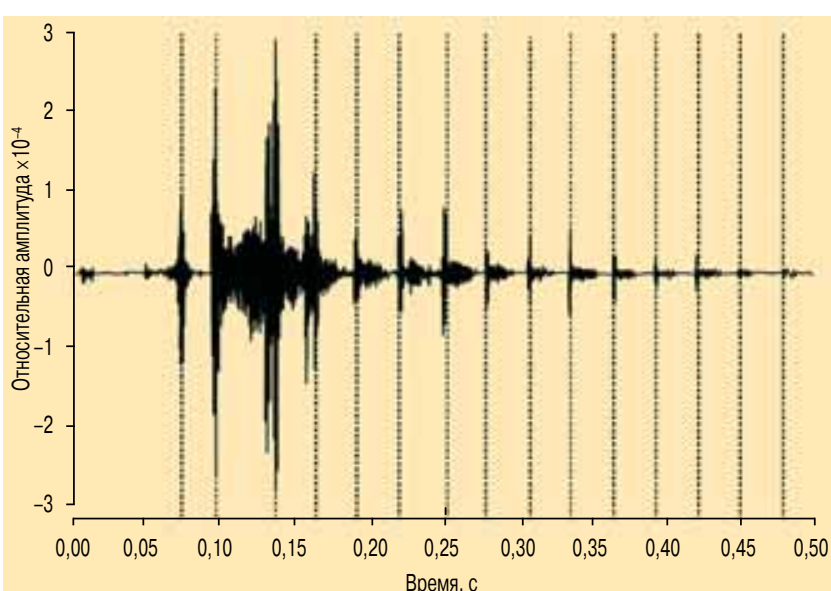

Рис. 5. Приступ кашля после 1-кратного вдоха с повторными "взрывными" фазами

существует четкая линейная зависимость между кашлевыми звуками и длительностью кашля (рис. 7).

\section{Другие конечные показатели при мониторировании кашля}

Помимо числа кашлевых эпизодов в качестве клинических показателей могут использоваться другие параметры кашлевого сигнала:

1. Имеет значение интенсивность кашля. Даже небольшое количество кашлевых эпизодов может доставлять сильное беспокойство, если они со-

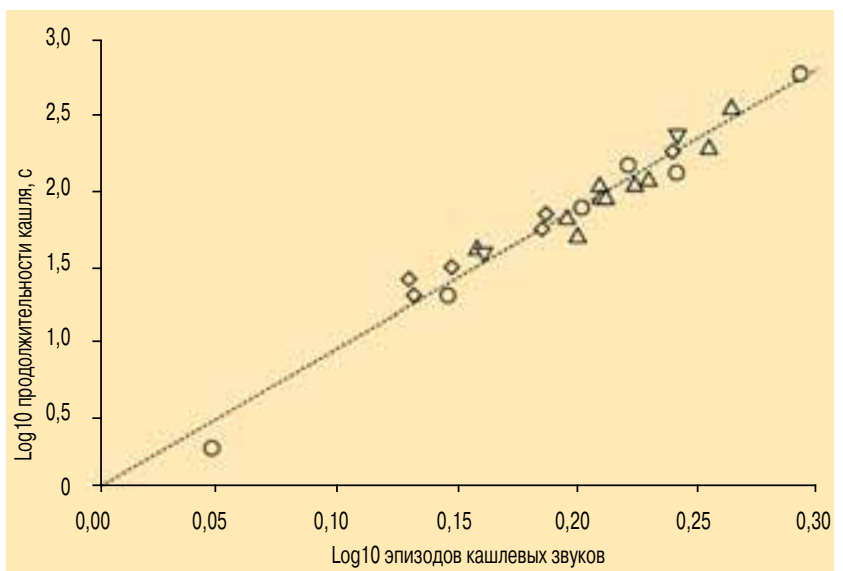

Рис. 7. Сравнение количественной оценки кашля при измерении продолжительности кашля в секундах и подсчете эпизодов кашлевых звуков при различных заболеваниях: $\Delta-$ муковисцидоз, $\diamond-$ идиопатический легочный фиброз, о - БА, $\nabla-$ ХОБЛ. Пунктиром обозначена линия наилучшего соответствия

провождаются болью в груди, рвотой или потерей сознания. Важными параметрами могут быть пиковая интенсивность кашля или общая энергия, затраченная на него.

2. Паттерн кашля (приступы кашля или отдельные кашлевые толчки) могут не только менять ощущения пациента, но и иметь разные механизмы. Более того, частота кашля в течение дня и ночи
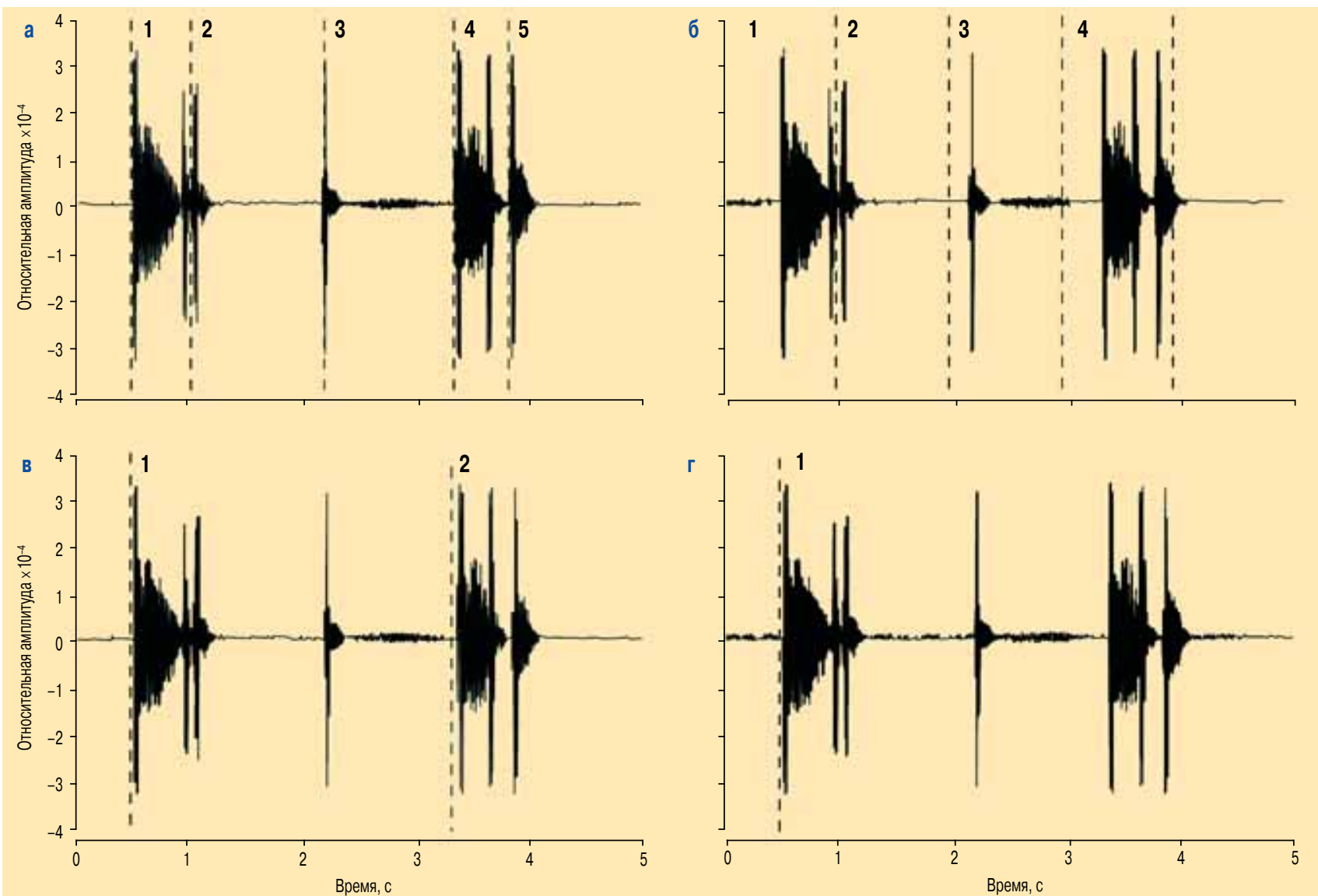

Рис. 6. Различные методы количественной оценки кашля: а) эпизоды кашлевых звуков; б) продолжительность кашля в секундах; в) кашлевые вдохи; г) приступы кашля. Пунктиром выделены единицы подсчета кашля, цифры представляют его количественное выражение 
может быть связана с влиянием провоцирующих кашель факторов [81].

3. Акустические свойства кашлевых звуков имеют теоретическое значение для выявления скоплений секрета в дыхательных путях или хрипов.

Для проведения исследований с целью изучения этих дополнительных параметров необходима автоматическая идентификация кашля. Поскольку его частота может меняться каждый час, имеет суточные колебания и зависит от ситуации, необходимо проводить амбулаторное мониторирование в течение 24 ч в привычной для пациента обстановке.

\section{Валидизация мониторирования кашля}

Требуется валидизация методов мониторования кашля при сравнении их с "золотым стандартом". Хотя ручной подсчет кашля по видео- или аудиозаписи является трудоемким [79, 88], он дает близкие результаты у разных исследователей.

Преимущества видеозаписи - в том, что можно увидеть движения, связанные с кашлем, но мониторирование ограничено зоной охвата видеокамеры, и информативность исследования у пациента с высокой физической активностью может снижаться. Валидизация амбулаторного мониторирования кашля возможна при использовании небольшого цифрового звукозаписывающего устройства и микрофона, который включается одновременно с мониторированием кашля [71].

Помимо этого, при разных заболеваниях меняются акустические свойства кашля [87, 89], поэтому ценность метода также будет различной. Таким образом, диагностика кашля должна быть валидизирована у больных с хроническим кашлем разной этиологии.

\section{Чувствительность и специфичность}

Чувствительность, специфичность, положительные и отрицательные прогностические значения также должны учитываться при разработке методов мониторирования кашля. Поскольку за кашель ошибочно можно принять другие звуки (например, разговор, прочищение горла, смех и сморкание), которые возникают чаще, следует регистрировать природу и количество ложноположительных результатов. Сравнение автоматического и ручного подсчета кашлевых толчков [90] дает четкое представление о различии этих 2 методов, связанном с масштабом измерения.

Важными характеристиками являются также воспроизводимость и чувствительность мониторинга кашля. Точность всех этих параметров (95\%-ный доверительный интервал) позволяет оценить постоянство метода.

\section{Дальнейшие исследования}

В последние годы произошел значительный прогресс в разработке полностью автоматизированных систем подсчета кашля, но все они требуют широкомасштабного тестирования. Точные счетчики кашля добавят новый показатель к его оценке. Простой подсчет - это только 1 составляющая в оценке кашля, и, вероятно, он объясняет только часть ощущений пациентов. Другие показатели, такие как интенсивность кашля, паттерны кашля как в течение короткого, так и длительного времени, акустические параметры (выявляющие хрипы и наличие секрета дыхательных путях), нуждаются в дальнейшем подробном изучении.

\section{Рекомендации}

1. В настоящее время отсутствует "золотой стандарт" регистрации кашля.

2. Аппаратура должна быть переносной и регистрировать кашель в цифровом формате и в течение длительного времени (24 ч).

3. На данный момент ни один метод количественной оценки кашля не имеет преимуществ перед другими.

\section{Оценка качества жизни больных с хроническим кашлем}

Хронический кашель нередко воспринимают как обычное явление, но он может значительно ухудшать качество жизни [8, 9]. До недавнего времени не было способов оценки качества жизни, связанного с кашлем. Хорошо валидизированные показатели исхода при хроническом кашле крайне скудны. Единое определение качества жизни, связанного со здоровьем, также отсутствует, хотя определение здоровья, разработанное Всемирной организацией здравоохранения ("состояние полного физического, психического и социального благополучия, а не простое отсутствие болезней"), принято широко в мире [91]. Оценка состояния здоровья или качества жизни, связанного со здоровьем, является стандартизованным и объективным способом количественной оценки влияния болезни или ее симптомов на повседневную жизнь пациента и его общее благополучие. Стандартными конечными показателями во многих рандомизированных контролируемых исследованиях являются данные вопросников, посвященных качеству жизни. В данном разделе рассматриваются влияние хронического кашля на состояние здоровья и оценка качества жизни у таких больных.

\section{Нежелательное влияние кашля на состояние здоровья}

Кашель оказывает значительное влияние на состояние здоровья. Причины, по которым больные с хроническим кашлем обращаются за медицинской помощью, могут быть связаны с беспокойством, чувством неловкости или сопутствующими симптомами, такими как рвота [92]. Острый кашель оказывает временное влияние на состояния здоровья. Влияние хронического кашля на здоровье варьируется от минимального у некоторых больных, которые не обращаются к врачу, до инвалидизирующего у других, когда ухудшение качества жизни сравнимо с таковым при хронических респираторных заболеваниях, таких как ХОБЛ. При этом обычно нарушаются и физическая, и психологическая, и социальная составляющие здоровья [9]. Больные с хроническим 
кашлем часто жалуются на мышечно-скелетные боли в грудной клетке, нарушение сна и охриплость голоса. Могут появляться и более выраженные симптомы, например потеря сознания, недержание мочи, рвота. У некоторых пациентов неприятные ощущения связаны с позывом к кашлю и его подавлением. Психологический аспект нарушения здоровья при кашле - боязнь серьезных болезней, например рака и туберкулеза.

Влияние кашля на социальную сферу определяется индивидуальными обстоятельствами. Он может мешать общаться, посещать публичные места, работать, отдыхать. Для изучения многообразия влияния кашля, особенно хронического, на состояние здоровья требуются подробные данные о сопутствующих кашлю симптомах.

\section{Оценка состояния здоровья \\ Шкалы для оценки кашля, дневники и визуально-аналоговые шкалы}

В клинических исследованиях широко используются шкалы [93], дневники [27, 94, 95], вопросники по оценке симптомов [96, 97] и визуально-аналоговые шкалы (ВАШ) [98], но все эти средства не были тщательно валидизированы. В большинстве методов изучения симптомов используются вопросы о частоте кашля, но более вероятно, что при этом измеряется комбинированный показатель тяжести кашля, который включает в себя частоту и интенсивность кашля, настроение и качество жизни больного. Очень мало известно о взаимосвязи этого показателя с другими характеристиками тяжести кашля, такими как объективная частота кашля и чувствительность кашлевого рефлекса. В отличие от вопросников по качеству жизни, дневники кашля и ВАШ не могут оценить различные компоненты состояния здоровья.

Дневники кашля содержат вопросы о частоте кашля [75]. Они слабо коррелируют с объективной оценкой частоты дневного кашля и совсем не коррелируют с ночным кашлем [75]. Нет данных о воспроизводимости и чувствительности дневников кашля и их взаимосвязи с другими параметрами тяжести кашля, такими как чувствительность кашлевого рефлекса, у пациентов с хроническим кашлем. У детей воспроизводимость вопросников по кашлю, заполняемых родителями, низкая [97]. Дневники кашля, заполняемые самими детьми, демонстрируют хорошую чувствительность и лучше коррелируют с объективной частотой кашля [94]. Интересно, что дневники кашля, заполняемые детьми, лучше коррелируют с объективной частотой кашля, чем такие же дневники, заполняемые родителями [94].

ВАШ представляет собой линейку длиной 100 мм, на которой пациент обозначает степень тяжести кашля: 0 мм соответствует отсутствию кашля, 100 мм самому сильному кашлю (рис. 8). Важно, чтобы больной получил четкую инструкцию о периоде времени, к которому относится данная оценка. Такая ВАШ хорошо воспроизводима в течение 2 нед. у больных с кашлем на фоне ХОБЛ (стандартное

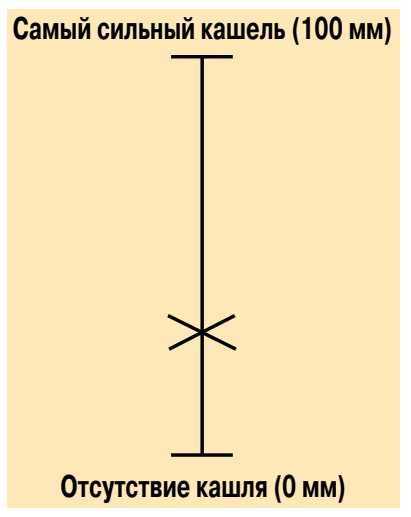

Рис. 8. Визуально-аналоговая шкала оценки кашля. Крестом обозначается тяжесть кашля в последние 2 нед. отклонение для каждого пациента - 7,8 мм, коэффициент внутриклассовой корреляции - 0,87) [99], а также высокочувствительна в клинических исследованиях у пациентов с хроническим кашлем, когда она используется как показатель исхода [9, 100, 101]. Установлена сильная корреляция оценки кашля по ВАШ с качеством жизни, связанным с кашлем, но отсутствует корреляция с чувствительностью кашлевого рефлекса [9]. Неизвестна взаимосвязь ВАШ с объективной частотой кашля.

\section{Вопросники качества жизни}

Вопросники качества жизни позволяют облегчить общение с пациентами и получить информацию о выраженности беспокоящих их проблем. Представления о влиянии заболевания на здоровье и предпочтения в лечении у больного и врача часто различаются, поэтому обязательно следует учитывать мнение пациента. Проще всего оценить качество жизни, расспросив пациента [102]. Недостаток данного метода в том, что некоторые исследователи плохо знают мнение своих пациентов. Обследование с помощью любых способов оценки качества жизни аналогично структурированной истории болезни, хотя показатели исхода объективны, валидизированы и выражаются количественно. Нередко в вопросниках оценивают отдельно эмоциональное и психологическое благополучие, физические и практические аспекты повседневной жизни. Вопросники могут быть общими или специфическими (для конкретного заболевания). Общие вопросники применяются у всех пациентов, независимо от заболевания. Балльная оценка качества жизни позволяет сравнивать пациентов с разными заболеваниями или больных со здоровыми людьми [103]. Однако общие вопросники недостаточно специфичны, не отражают особенностей состояния больного и менее чувствительны к специфическим вмешательствам, чем вопросники, предназначенные для конкретного заболевания.

В результате были разработаны 3 вопросника для оценки качества жизни у больных с хроническим кашлем: вопросник качества жизни, связанного с кашлем (Cough-Specific Quality-of-Life QuestionnaireCQLQ), вопросник кашля Лейчестера (Leicester Cough Questionnaire - LCQ) и вопросник влияния хронического кашля (Chronic Cough Impact Questionnaire CCIQ) $[8,9,104]$. 


\section{Вопросники качества жизни, связанного с кашлем}

Недавно опубликован разработанный в Северной Америке вопросник CQLQ, который состоит из 28 пунктов [8]. Он предназначен для взрослых с острым и хроническим кашлем. Вопросник заполняется пациентом и содержит шкалу Ликерта с 4 пунктами ответов. Все вопросы сгруппированы в 6 разделов: физические жалобы, чрезвычайные физические жалобы, психологические проблемы, эмоциональное благополучие, тревога о собственной безопасности и функциональные возможности. Вопросы отбирались исследователями и изучались посредством факторного анализа, который представляет собой психометрический метод, во многом основанный на структуре корреляций между вопросами, хотя в процессе анкетирования исследователи должны принимать немало субъективных решений. Недостаток факторного анализа в том, что он не учитывает восприятие клинических вопросов исследуемой популяцией. Предварительная версия CQLQ, названная Исследованием нежелательных исходов кашля ( $A d$ verse Cough Outcome Survey - ACOS) [92], оценивалась по текущей валидности, т. е. в сравнении с другими стандартами-индикаторами точности измерений. ACOS умеренно коррелирует с общим вопросником качества жизни Sickness Impact Profile. Вопросник CQLQ воспроизводим и чувствителен к изменениям состояния пациентов с хроническим кашлем, но эти качества не изучались у больных с острым кашлем. Взаимосвязь между CQLQ, чувствительностью кашлевого рефлекса и объективной частотой кашля неизвестна. В настоящее время ведутся исследования по определению минимальных клинически значимых изменений результатов вопросника.

\section{Вопросник кашля Лейчестера}

Этот краткий, легкий в применении и хорошо валидизированный вопросник разработан в Великобритании [9]. Он состоит из 19 пунктов и 3 разделов (физического, психологического и социального). Вопросник заполняется самими пациентами и содержит шкалу ответов Ликерта из 7 пунктов. Одно из основных отличий LCQ от CQLQ - в том, что вопросы для него отбирали с помощью факторного анализа клинического влияния признаков. Этот метод позволяет выбрать вопросы, отмеченные больными как наиболее важные, и расположить их в порядке значимости. Вопросы группируются в разделы по клинической чувствительности. LCQ активно валидизировался в сравнении с другими вопросниками по качеству жизни и способами оценки тяжести кашля [9]. Он воспроизводим и чувствителен у больных с хроническим кашлем, а также чувствителен при остром кашле [9, 105]. Предварительные данные свидетельствуют, что LCQ коррелирует с объективной частотой кашля у больных с хроническим кашлем [82]. Минимальные клинически значимые изменения LCQ при хроническом кашле составляют 1,3 балла [106]. Минимальные клинически значимые изменения LCQ при остром кашле в настоящее время изучаются. LCQ является чувствительным по- казателем, который может использоваться как основной параметр исхода в клинических исследованиях у больных с хроническим кашлем [107]. LCQ можно получить в электронной версии [9].

\section{Вопросник влияния хронического кашля}

Вопросник влияния хронического кашля CCIQ недавно разработан в Италии [104]. Он состоит из 24 пунктов, сгруппированных в 4 раздела (сон / концентрация внимания, влияние на взаимоотношения, влияние на повседневную жизнь и настроение), и содержит шкалу Ликерта из 5 пунктов. Это короткий и простой в использовании вопросник. Данных по валидизации CCIQ пока недостаточно [104]. Воспроизводимость и чувствительность вопросника не описаны, минимальные клинически значимые изменения и взаимосвязь с другими показателями тяжести кашля также не изучены.

\section{Состояние здоровья при хроническом кашле}

Влияние кашля на состояние здоровья изучено недостаточно. Однако имеются предварительные данные исследований с использованием специализированных вопросников. Качество жизни значительно ухудшается при остром кашле - в одинаковой степени у мужчин и женщин [108]. При хроническом кашле качество жизни также снижается, причем у женщин в большей степени, чем у мужчин [109], и не зависит от возраста, длительности или этиологии кашля [92, 110]. Психологические расстройства особенно часты у больных с хроническим кашлем, при этом преобладают депрессивные симптомы [109-111]. Доказано, что после специфической терапии кашля состояние здоровья значительно улучшается [8, 9].

В одном из последних исследований у больных с хроническим кашлем, живущих в Турции, сравнивались переведенные вопросники LCQ и CQLQ, В результате чего получена умеренная корреляция между ними [112]. Оба вопросника показали хорошую валидность и чувствительность, что позволяет предположить, что их можно адаптировать к пациентам других языков и культур.

Итак, хронический кашель может значительно влиять на качество жизни. При ведении больных с хроническим кашлем следует оценивать состояние их здоровья. Вопросники LCQ, CQLQ и CCIQ предназначены для взрослых больных с хроническим кашлем. Они также могут применяться для долговременной оценки пациентов с хроническим кашлем и выявления наиболее острых проблем. Вопросники по качеству жизни должны использоваться в дополнение к объективным маркерам тяжести заболевания и оценке эффективности лечения в клиниках и клинических исследованиях и при анализе стоимости / эффективности.

\section{Дальнейшие исследования}

Необходимо определить минимальные клинически значимые изменения результатов вопросников и изучить взаимосвязь между качеством жизни и дру- 
гими маркерами тяжести кашля. Ожидаются клинические исследования, основным конечным показателем которых будет качество жизни, связанное с кашлем.

\section{Рекомендации}

1. Кашель может оказывать значительное влияние на состояние здоровья, которое оценивается по специальным вопросникам.

2. Для оценки тяжести кашля у больных с хроническим кашлем можно использовать ВАШ.

3. В клинических исследованиях состояние больных с хроническим кашлем должны оцениваться по вопросникам качества жизни, специфичным для кашля.

\section{Модели кашля в экспериментах}

Кашель - это рефлекторный защитный механизм и наиболее частый симптом многих воспалительных заболеваний дыхательных путей [113]. В настоящее время не разработана достаточно эффективная тактика лечения острого кашля, что подчеркивается в недавно опубликованном обзоре, посвященном противокашлевым лекарственным препаратам [114]. Поиск новых методов продолжается. Однако прежде чем будет исследоваться эффективность новых препаратов у человека, они должны пройти испытания на животных. Основной целью создания моделей на животных является изучение механизмов действия и тестирование новых лекарств. Эти модели должны быть надежными и воспроизводимыми и по возможности максимально точно соответствующими заболеванию человека.

\section{Образцы}

Большинство доклинических исследований нервных путей, участвующих в кашлевом рефлексе, и их фармакологической регуляции выполняются на мышах, крысах, морских свинках, кроликах, кошках и собаках [115] и чаще - на свиньях.

У грызунов кашлевой рефлекс трудно изучать, если животному выполнена анестезия, которая подавляет нервную проводимость и активность центральной нервной системы (ЦНС). Однако несколько исследователей использовали неанестезированных крыс для изучения влияния потенциальных противокашлевых препаратов. Хотя многие работы выполнялись на неанестезированных крысах и регистрировали кашлевые звуки [117], существуют сомнения относительно существования у этих животных кашлевого рефлекса, аналогичного человеческому. Действительно, если можно воспроизвести кашель у крыс, основной рефлексогенной кашлевой зоной должна быть гортань, а не трахеобронхиальное дерево [13]. Экспульсивные эпизоды, происходящие из гортани, могут затрагивать экспираторные рефлексы, которые трудно отличить от кашля. Более того, регуляция этих 2 рефлексов происходит по-разному [118]. В других исследованиях описаны модели кашля на мышах [119], но их использование по-прежнему ограничено, учитывая, что у мышей нет быстро адаптирующихся рецепторов (которые, как предполагается, наряду с афферентными С-волокнами играют важную роль в формировании кашлевого рефлекса), у них недостаточно внутриэпителиальных нервных окончаний и кашлевой рефлекс, по-видимому, отсутствует [119]. Показано, что мыши не могут кашлять [13], т. к. не могут вырабатывать необходимую для этого энергию. В связи с этим существует мнение, что исследователи, использующие такие модели, измеряют экспираторный рефлекс, а не истинный кашель.

При использовании в экспериментах крупных животных, таких как кошки, собаки и свиньи, следует учитывать их стоимость, включающую не только цену животного, но и затраты на питание, содержание и большое количество лекарственных веществ для скрининга. В связи с этим применение таких моделей для рутинного скрининга почти полностью исключается, но они могут применяться при третичном скрининге.

В последние годы наиболее часто кашель моделируется на морских свинках $[120,121]$. В таких экспериментах было получено немало информации о физиологической [122] и фармакологической регуляции кашлевого рефлекса. Кашель моделировали, помещая морских свинок в прозрачную камеру из перспекса и подвергая воздействию туссогенного аэрозоля, при этом измеряли кашлевые звуки [123-125].

\section{Моделирование кашля на морских свинках}

Морские свинки являются самыми полезными лабораторными животными, по сравнению с кроликами и мышами, в экспериментальных исследованиях химически индуцированного кашля [126]. Кашель индуцируют у неанестезированных морских свинок путем ингаляции аэрозоля капсаицина либо раствора с низким pH, например раствора лимонной кислоты [10, 123, 127-129]. В таких экспериментах эффективно моделируется кашлевой рефлекс человека, что подтверждено в исследовании, показавшем сходство реакции на лимонную кислоту и капсаицин у человека и морской свинки [10]. Более того, недавно полученные in vitro данные позволяют предположить, что изолированный вагус морской свинки деполяризуется в ответ на кашлевые стимулы так же, как и изолированный нерв человека [130].

В то же время результаты моделирования у морских свинок и у человека различаются. Хотя и морская свинка, и человек одинаково реагируют появлением кашля на капсаицин, это вещество (а также лимонная кислота - в меньшей степени) вызывает у морских свинок тахипноэ [10]. Более того, если локальное высвобождение субстанции Р из нервных окончаний C-волокон тем или иным образом участвует в формировании кашля, это может приводить к различиям кашлевого рефлекса, учитывая малое количество нервов, содержащих нейропептиды, в дыхательных путях человека. Помимо этого, морская свинка всегда дышит носом, что тоже может быть причиной различий. Наконец, продемонстрированная активность некоторых молекул у животных 
и недоказанная их эффективность у человека свидетельствуют, что данные, полученные на таких моделях, не могут прогнозировать ситуацию у человека.

\section{Сравнение анестезированных и неанестезированных животных}

Трудно изучать кашлевой рефлекс у анестезированных грызунов, т. к. анестезия подавляет нервную передачу и активность ЦНС. Тем не менее у некоторых видов можно создать определенную глубину анестезии при непременно интактном дыхательном рефлексе и легко измерить кашлевой ответ [115, 131, 132]. Примером такой модели могут быть анестезированные кошки, которых используют для изучения центральных эффектов противокашлевых лекарственных средств, вводимых внутрь желудочков мозга [133], и периферических эффектов лекарственных веществ, вводимых внутривенно [134]. В этих экспериментах кашель, возникающий в ответ на механические и химические стимулы, характеризуется глубоким вдохом, после которого следует активное экспираторное усилие. В других экспериментах кашель у анестезированных животных определялся как большой всплеск электромиографической активности диафрагмы сразу после всплеска активности прямых мышц живота [135]. B.J.Canning et al. [131] недавно показали, что капсаицин и брадикинин (стимуляторы С-волокон) в целом не могут инициировать кашлевой рефлекс у анестезированных морских свинок, даже если он полностью сохраняется в ответ на механические раздражители (в основном селективные к быстро адаптирующимся рецепторам). Аналогичным образом M.Tatar и R.Pecova [136] показали, что у морских свинок, анестезированных уретаном, механическое раздражение гортани и трахеобронхиального дерева не всегда вызывает кашель. Ингаляция аэрозоля капсаицина не меняет паттерн дыхания и не может вызывать кашель. Однако эти химические вещества провоцируют кашель у неанестезированных морских свинок, что позволяет предположить, что при изучении кашлевого рефлекса на моделях животных лучше не прибегать к анестезии.

\section{Методология}

В литературе описана процедура измерения кашля у неанестезированных морских свинок [10, 120, 124-127]. Животное помещают в небольшую камеру из перспекса (емкостью 1 л), в которой она может свободно двигаться во время экспозиции аэрозоля. Некоторые исследователи применяют 2-камерный бодиплетизмограф [137]. Поток воздуха через камеру обеспечивается сжатым медицинским воздухом через регулятор потока со скоростью 600 мл/мин. Изменения воздушного потока за счет дыхания и кашля определяются пневмотахографом, усиливаются и записываются бумажным писчиком или компьютером. Кашлевые звуки также усиливаются через преобразователь давления и записываются через микрофон, помещенный в камеру, в цифровом формате. Туссогенные вещества (капсаицин, лимонная кислота и др.) распыляются в камеру через ультразвуковой небулайзер с выходом 0,4 мл/мин и средним диаметром частиц 1 мкм. Животное подвергается воздействию туссогенного аэрозоля в течение определенного времени, обычно не более 10 мин в зависимости от вещества, провоцирующего кашель. Рекомендуется строить кривую зависимости дозаответ для каждого индуктора кашля и для дальнейших исследований выбирать субмаксимальную дозу. В других протоколах применяют аэрозоль лимонной кислоты в постепенно возрастающей концентрации (0,05-1,6 моль) с длительностью воздействия каждой концентрации 30 с. Кашель записывается в течение 30-секундной ингаляции каждой концентрации индуктора кашля и во время последующего наблюдения - в течение 60 с. Таким образом, интервал между воздействиями составляет 1,5 мин. Число кашлевых эпизодов от воздействия каждой концентрации сравнивают с контрольной группой. Если существенная разница появляется при ингаляции меньшей концентрации, говорят об изменении чувствительности кашлевого рефлекса [138].

Очень трудно дифференцировать кашель от других рефлексов, возникающих в верхних дыхательных путях, поэтому он должен оцениваться 3 различными способами для уверенности в том, что регистрируется только кашель, а втягивания воздуха носом и усиленное дыхание исключаются. Эти 3 метода заключаются в следующем:

1) наблюдение (или видеозапись) для дифференцирования кашля от носовых звуков и выявление изменений в положении тела (расставленные передние лапы и вытянутая вперед шея) и характерного открывания рта, связанного с кашлем;

2) регистрация давления или изменений воздушного потока, отражающих глубокий вдох и резкий выдох, возникающие во время кашля;

3) отслеживание характерных звуков, которые издает кашляющая морская свинка.

Результат можно представить как число эпизодов кашля за 1 мин или за 10 мин и сравнить их с аналогичными у животных группы плацебо.

\section{Кашлевые стимуляторы}

Кашлевой рефлекс можно вызвать электрическими, механическими (у анестезированных животных) или химическими раздражителями, а также изменениями концентрации ионов или осмолярности жидкости, выстилающей слизистую оболочку сенсорных областей (гортани, трахеи, бронхов), либо стимуляцией ЦНС. В недавних исследованиях с этой целью использовали ирритант капсаицин и растворы с низким рН (например, лимонную кислоту). Преимущество лимонной кислоты - в том, что она позволяет проводить повторные измерения кашля без развития тахифилаксии, в то время как повторные воздействия капсаицина, как известно, приводят к этому феномену и не позволяют получить воспроизводимый кашлевой ответ у одного и того же животного [25, 138]. Различные методы стимуляции воздействуют на разные группы сенсорных афферентных 
структур, что стало причиной дискуссии о селективности веществ для различных типов волокон, например об использовании капсаицина как селективного стимулятора С-волокон [124, 139].

\section{Дизайн экспериментов}

Животных следует содержать в одинаковых условиях и часто менять подстилки, т. к. скопление в клетке азотосодержащих продуктов может повышать кашлевой ответ на лимонную кислоту [140]. M.G.Belvisi et al. (данные не опубликованы) показали, что кашлевой ответ на указанные стимулы значительно варьируется у разных особей морских свинок, но повторный тест у того же животного хорошо воспроизводим с лимонной кислотой, но не с капсаицином. Следовательно, разумно проводить эксперименты и сравнивать результаты в разных группах животных - исследуемой и плацебо, а не у одного и того же животного до и после лечения препаратом или плацебо. Однако природная вариабельность у неанестезированных животных предполагает, что в исследование следует включать 8-12 особей.

\section{Модели заболеваний}

Известно, что многие заболевания легких сопровождаются усилением кашля. Однако механизмы, вовлеченные в эти усиленные реакции, неизвестны.

\section{Модели аллергии}

Большинство экспериментов проводятся на морских свинках и демонстрирует усиление кашля в ответ на капсаицин спустя не менее 1 сут. после провокации антигеном у сенсибилизированных животных [141, 142]. Повышение кашлевого ответа связано с эозинофилией. Определенную роль в усилении кашлевого ответа у аллергичных морских свинок, вероятно, играют тахикинины, поскольку усиленный капсаицином кашлевой ответ после антигенной провокации подавляется антагонистами рецепторов нейрокининов $\mathrm{NK}_{1}, \mathrm{NK}_{2}$ по отдельности и совокупно $\left(\mathrm{NK}_{1} / \mathrm{NK}_{2}\right)$ [141]. Кашель в ответ на механическое раздражение трахеи усиливается и у сенсибилизированных анестезированных собак после провокации пыльцой [143].

\section{Модели постназального синдрома}

Хронические заболевания носа и придаточных пазух (например, аллергический и неаллергический риниты, синусит, вазомоторный ринит) также являются частыми причинами хронического кашля [7]. Этот феномен продемонстрирован на модели животных, когда раздражение афферентных рецепторов носа капсаицином после назальной антигенной провокации усиливало экспериментально вызванный кашель у сенсибилизированных кошек и морских свинок $[137,138]$.

\section{Ингибиторы ангиотензин-превращающего фермента}

Длительное систематическое лечение некоторыми ингибиторами ангиотензин-превращающего фермента (ИАПФ) усиливает спонтанный и индуциро- ванный ирритантами кашель у морских свинок [124, $144,145]$.

\section{Табачный дым}

Длительное вдыхание (активное или пассивное) сигаретного дыма может усиливать кашлевой ответ у морских свинок [146-148]. В некоторых случаях это может сопровождаться скоплением в дыхательных путях эозинофилов и нейтрофилов [146]. В 1 исследовании пассивное курение табака повышало кашель, индуцированный лимонной кислотой, и бронхоконстрикцию; этот эффект блокировался введением антагонистов рецепторов $\mathrm{NK}_{1}$ в ядра солитарного тракта головного мозга [147].

Воспалительный процесс, смоделированный у некоторых животных, вероятно, может менять фенотип и / или возбудимость сенсорных афферентных рецепторов в дыхательных путях [149-151], что активизирует их участие в центральных контролирующих механизмах кашля. Механизмы повышенной чувствительности пока изучены недостаточно, но исследование специфических путей, усиливающих этот рефлекс, может привести к открытию более эффективных методов лечения.

Итак, кашель независимо от вызвавшего его заболевания органов дыхания представляет собой насущную клиническую проблему. В настоящее время его лечение оказывается неэффективным [114]. Разработка новых действенных методов терапии возможна только при моделирования кашля на животных при точном воссоздании соответствующих состояний человека. Эксперименты на морских свинках имеют определенные преимущества, т. к. эти грызуны могут кашлять в ответ на раздражители, не будучи анестезированными, и физиология кашлевого ответа у них аналогична таковой у человека. Поэтому рекомендуется использовать в исследовательских целях именно этих животных.

\section{Рекомендации}

1. Наиболее информативным является моделирование кашля у неанестезированных морских свиHOK.

2. Эпизод кашля должен оцениваться как по звукам, так и по воздушному потоку.

\section{Дизайн и проведение клинических исследований противокашлевых препаратов}

В связи с тем, что острый кашель - крайне распространенное явление, а в хронической форме он нередко нарушает жизнь и работоспособность больного, неудивительно, что в настоящее время разрабатываются новые методы противокашлевой терапии - как специфической, так и неспецифической. Кашель у человека и животных различается, поэтому лекарственные вещества, высокоэффективные в экспериментах на животных, например антагонисты рецепторов NK, не дают результата в клинической практике [152]. Установление эффективности или неэффективности лекарства у человека сопряжено с множеством трудностей, 
в т. ч. выбором модели, набором участников, выбором оцениваемых показателей, применимостью в клинических исследованиях и преодолением эффекта плацебо. Данный раздел содержит рекомендации по повышению шансов получить истинные результаты в любом клинико-фармакологическом исследовании.

\section{Выбор модели}

В клинических условиях кашель, требующий назначения специфической терапии, отличается от кашля, индуцированного в эксперименте у здоровых добровольцев, поскольку болезнь повышает чувствительность кашлевого рефлекса. Это относится как к острому [29], так и к хроническому кашлю [22, 24], при котором кривая доза-ответ кашлевого провокационного теста смещается влево и возвращается к норме либо спонтанно [29], либо после медикаментозного лечения [101, 153, 154]. Молекулярная основа гиперчувствительности кашлевого рефлекса неизвестна. Достаточным объяснением, вероятно, может быть воспалительный процесс в дыхательных путях, приводящий к гиперчувствительности периферических кашлевых рецепторов, например при остром вирусном бронхите. Продемонстрирована пролиферация нервов, содержащих предполагаемые

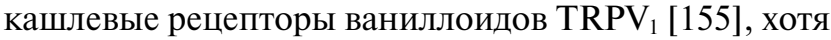
экспрессия этих рецепторов не может ограничиваться только сенсорными нейронами [156]. Исследования на животных подтвердили гипотезу, что сенсибилизация возникает в вагальных ганглиях, расположенных в местах соединения узловых и яремных парасимпатических ганглиев [157]. Центральная регуляция и гиперчувствительность кашлевого рефлекса возникает обязательно [31]. Следовательно, при планировании исследований противокашлевой активности лекарств информация об их предполагаемом механизме действия крайне важна. Например, антагонисты лейкотриенов воздействуют на кашлевой вариант БА [153] и являются одним из основных видов лечения при неэффективности ингаляционных стероидов. Однако кашлевые провокационные тесты на моделях классической БА не подтвердили эффективность данного класса лекарств [158]. Это связано с тем, что чувствительность кашлевого рефлекса повышается за счет астматического воспаления, в частности, за счет скопления тучных клеток вокруг нервных волокон в дыхательных путях [159]. При отсутствии воспаления влияние антилейкотриеновых препаратов отсутствует. Напротив, при разработке антагонистов капсаициновых рецепторов $\mathrm{TRPV}_{1}$ будет логичным предположить, что эффективный препарат должен блокировать кашлевую провокацию капсаицином у здоровых добровольцев.

Кашель является жизненно важным защитным рефлексом. Состояния с выраженным снижением кашлевого рефлекса, например инсульт, болезнь Паркинсона, сопровождаются повышением частоты аспираций и аспирационных пневмоний. Таким образом, следует осторожно подходить к планированию клинических исследований по неспецифической супрессии кашля. Супрессия кашля, вызванного вирусным бронхитом, вряд ли приведет к нежелательным последствиям, но супрессия кашля в исследованиях в популяции больных с хроническим продуктивным кашлем может привести к инспирации бронхиального секрета и ухудшению клинического состояния. Однако даже при повышении продукции бронхиальной слизи чувствительность кашлевого рефлекса может быть избыточной. Требуются дальнейшие исследования, чтобы выяснить, к какому результату приводит супрессия патологически повышенной чувствительности кашлевого рефлекса до нормального уровня - к улучшению или ухудшению.

\section{Исследования с участием здоровых добровольцев}

Исследования с участием здоровых добровольцев почти всегда проводятся с использованием кашлевой провокации. Чаще применяют 2 методики: с капсаицином и лимонной кислотой [25]. Они позволяют оценить чувствительность кашлевого рефлекса различным образом, поэтому корреляция между результатами этих тестов у одного и того же человека будет слабой. Тем не менее оба теста применяются для оценки противокашлевых эффектов. Мало известно о связи результатов данных проб с клиническими ситуациями, и это является "слабым звеном" кашлевых провокаций у здоровых лиц.

Отбор здоровых добровольцев должен включать в себя скрининговый визит, во время которого и проводится провокационный кашлевой тест. Лица с кашлевой реакцией только на высокие концентрации индуцирующего вещества исключаются из исследований. У таких людей трудно выявить супрессию кашля, поскольку они уже получили максимальную переносимую дозу, и побочные неспецифические эффекты провоцирующих веществ - ощущение жжения при ингаляции капсаицина или удушья при ингаляции лимонной кислоты - могут маскировать терапевтическое воздействие изучаемых противокашлевых препаратов [18].

\section{Реакция на плацебо}

В исследованиях с применением провокационных кашлевых тестов у здоровых добровольцев важным фактором является плацебо. Плацебо может вызывать снижение кашлевой чувствительности в провокационном тесте более чем на $30 \%$, и этот эффект может сохраняться в течение нескольких часов [160]. Была смоделирована фармакокинетика плацебо в кашлевых провокационных тестах [39]. Предпринято немало попыток минимизировать эффект плацебо: выполнить скрининговый тест с плацебо под видом противокашлевого препарата и затем исключить всех испытуемых с положительной реакцией, рандомизировать прием провоцирующих кашель веществ либо привлекать к участию в исследовании лиц с ранее известной слабой реакцией на плацебо. Однако ни одна из этих стратегий не была эффективной, поэтому следует планировать исследование с учетом вероятности значительного ответа на плацебо, который может появиться, несмотря на все меры предосторожности. 
Пол

У женшин кашлевой рефлекс, как правило, усилен [49, 51]. В среднем при любом кашлевом провокационном тесте женщины кашляют вдвое больше, чем мужчины, или, наоборот, у женщин С2 и С5 ниже. Причина таких половых различий неизвестна, но они возникают и у пациентов, направленных в специализированные клиники по лечению кашля [22], и у больных, получающих ИАПФ [161]. Если учитывать этот факт при разработке критериев исключения, то в исследованиях с участием здоровых добровольцев не следует проводить различное лечение для мужчин и женщин.

\section{Исследования на здоровых добровольцах с воспалительным процессом в дыхательных путях}

Чтобы смоделировать у здоровых добровольцев кашель, максимально приближенный к клиническому, в исследования отбирали курильщиков с кашлем [162]. У них можно оценивать другой конечный показатель - кашель курильщика, кроме того, у них происходит воспалительный процесс в дыхательных путях. При проведении таких исследований следует помнить, что курение табака оказывает выраженное влияние на кашлевой рефлекс [163]. Действительно, у курильщиков чувствительность кашлевого рефлекса снижена и количество кашлевых эпизодов за час примерно вдвое меньше, чем у некурящих. Оценивать эффективность лекарственных препаратов лучше всего утром (после ночного периода без курения), даже у лиц, отказавшихся от курения на весь период исследования.

Хотя данная модель называется "натуральным кашлем", привлечение курильщиков в исследование может повлиять на результаты изучения некоторых препаратов. В частности, хорошо известно негативное влияние курения на эффективность ингаляционных стероидов [164].

\section{Исследования с участием больных}

Пожалуй, самые большие трудности в клинических исследованиях кашля представляет выбор изучаемой популяции.

\section{Острый кашель}

Острый кашель является доброкачественным саморазрешающимся состоянием, поэтому при наборе популяции следует учитывать его неизбежную спонтанную регрессию у значительного количества пациентов. Этот факт, наряду с мощным эффектом плацебо [165, 166], затрудняет проведение клинических исследований.

Наряду с суточной вариабельностью кашля перечисленные обстоятельства делают практически невозможным использовать перекрестный дизайн. Поскольку существуют индивидуальные различия в реакции, исследование в любых параллельных группах должно иметь большие размеры для убедительного подтверждения эффективности противокашлевых препаратов. Единственным на сегодняшний день мощным исследованием, продемонстрировав- шим противокашлевую эффективность при остром кашле, является метаанализ с участием > 300 больных [167]. В этом исследовании проведен трудоемкий аудиоанализ кашля. Цифровые устройства для записи кашля появились позже и позволили объективно оценивать его частоту, что стало "золотым стандартом" для дальнейших подобных исследований $[73,80,83,160]$. До этого момента конечными показателями служили субъективные шкалы для оценки кашля, ВАШ и совсем недавно - вопросники по качеству жизни [8, 9].

\section{Поствирусный кашель}

Кашель, который существует дольше произвольно установленного 2-недельного периода, может считаться поствирусным [6]. Как правило, он разрешается спонтанно, но пациенты с таким кашлем успешно включаются в исследования, например, для изучения влияния ингаляционных стероидов на поствирусный кашель. Набор больных происходит сезонно и иногда довольно медленно.

\section{Хронический кашель}

В определении хронического кашля существует путаница, что в некоторой степени объясняет большой разброс в частоте выявления различных кашлевых синдромов, по сообщениям специализированных клиник [168]. Таким образом, лучше отбирать больных в исследование по наличию или отсутствию какого-либо диагностического результата, а не по определениям, в которых отсутствует единое мнение. У больных ГЭРБ в результате аспирации может возникать бронхиальная гиперреактивность [169]. Аналогичным образом, у больных БА также могут быть проявления рефлюкса [170], поэтому при изучении астматического кашля лучше отбирать пациентов на основании положительного бронхопровокационного теста с метахолином или эозинофилии мокроты, а диагноз ГЭРБ должен быть объективно подтвержден.

Похожая ситуация существует у больных с классической астмой, когда включение в исследование требует положительного бронходилатационного теста, несмотря на то, что только лишь небольшой процент астматиков соответствует этому критерию.

Интересную для изучения группу составляют пациенты, которые не соответствуют диагностическим критериям синдрома кашля или были исключены из исследований соответствующей терапии. Их называют больными с идиопатическим кашлем, и они часто посещают специализированные клиники. В отличие от больных с острым кашлем, они не реагируют на плацебо и, поскольку кашель у них воспроизводим, могут участвовать в перекрестных исследованиях, однако число таких больных ограниченно [107].

\section{Дизайн и проведение клинических испытаний противокашлевых препаратов}

1. Выбор экспериментальной модели для исследования противокашлевого препарата во многом зависит от механизма его действия. 
2. Исследования с участием здоровых добровольцев должны планироваться с учетом большой вероятности эффекта плацебо.

3. Для изучения острого кашля требуются исследования в параллельных группах.

4. Для изучения хронического кашля больных следует отбирать в исследования по результатам диагностических тестов.

\section{Литература}

1. Office of Population Censuses and Surveys, Morbidity Statistics from General Practice: 4th National Study 19911992. Series MB5 no. 3. London: Her Majesty's Stationery Office; 1995.

2. Schappert S.M. Ambulatory care visits of physician offices, hospital outpatient departments, and emergency departments: United States, 1995. Vital Hith Stat. 1997; 13 (129): $1-38$.

3. Fendrick A.M., Monto A.S., Nightengale B., Sarnes M. The economic burden of non-influenza-related viral respiratory tract infection in the United States. Arch. Intern. Med. 2003; 163: 487-494.

4. Irwin R.S., Curley F.J., French C.L. Chronic cough. The spectrum and frequency of causes, key components of the diagnostic evaluation, and outcome of specific therapy. Am. Rev. Respir. Dis. 1990; 141: 640-647.

5. McGarvey L.P.A., Heaney L. G., MacMahon J. A retrospective survey of diagnosis and management of patients presenting with chronic cough to a general chest clinic. Int. J. Clin. Pract. 1998; 52: 158-161.

6. Morice A.H., Fontana G.A., Sovijarvi A.R.A. et al. The diagnosis and management of chronic cough. Eur. Respir. J. 2004; 24: 481-492.

7. Irwin R.S., Baumann M.H., Bolser D.C. et al. Diagnosis and management of cough executive summary. ACCP evidence-based clinical practice guidelines. Chest 2006; 129 (suppl. 1): 1S-23S.

8. French C.T., Irwin R.S., Fletcher K.E., Adams T.M. Evaluation of cough-specific quality of life questionnaire. Chest 2002; 121: 1123-1131.

9. Birring S.S., Prudon B., Carr A.J. et al. Development of a symptom specific health status measure for patients with chronic cough: Leicester Cough Questionnaire (LCQ). Thorax 2003; 58: 339-343. Online version: www.thorax. bmjjournals.com/cgi/content/full/58/4/339. Date updated: April 2003. Date accessed: January 2007.

10. Laude E.A., Higgins K.S., Morice A.H. A comparative study of the effects of citric acid, capsaicin and resiniferatoxin on the cough challenge in guinea-pig and man. Pulm. Pharmacol. 1993; 6: 171-175.

11. Dicpinigaitis P.V. Short- and long-term reproducibility of capsaicin cough challenge testing. Pulm. Pharmacol. Ther. 2003; 16: 61-65.

12. Widdicombe J., Fontana G. Cough: what's in a name? Eur. Respir. J. 2006; 28: 10-15.

13. Korpas J., Tomori Z. Cough and other respiratory reflexes. Basle: S. Karger; 1979.

14. Morice A.H., McGarvey L., Pavord I. Recommendations for the management of cough in adults. Thorax 2006; 61 (suppl. 1): i1-i24.

15. Collier J.G., Fuller RW. Capsaicin inhalation in man and the effects of sodium cromoglycate. Br. J. Pharmacol. 1984; 81: 113-117.

16. Bickerman H.A., Barach A.L., Itkin S., Drimmer F. Experimental production of cough in human subjects induced by citric acid aerosols. Preliminary studies on the evaluation of antitussive agents. Am. J. Med. Sci. 1954; 228: $156-163$.

17. Bickerman H.A., German E., Cohen B.M. The cough response of healthy human subjects stimulated by citric acid aerosol. Am. J. Med. Sci. 1957; 234: 191-205.

18. Midgren B., Hansson L., Karlsson J.A. et al. Capsaicininduced cough in humans. Am. Rev. Respir. Dis. 1992; 146: $347-351$.

19. Fujimura M., Kamio Y., Hashimoto T., Matsuda T. Cough receptor sensitivity and bronchial responsiveness in patients with only chronic nonproductive cough: in view of effect of bronchodilator therapy. J. Asthma 1994; 31: 463-472.

20. Dicpinigaitis P.V., Dobkin J.B. Antitussive effect of the GABA-agonist baclofen. Chest 1997; 111: 996-999.

21. Kopec S.E., DeBellis R.J., Irwin R.S. Chemical analysis of freshly prepared and stored capsaicin solutions: implications for tussigenic challenges. Pulm. Pharmacol. Ther 2002; 15: 529-534.

22. Kastelik J.A., Thompson R.H., Aziz I. et al. Sex-related differences in cough reflex sensitivity in patients with chronic cough. Am. J. Respir. Crit. Care Med. 2002; 166: 961-964.

23. Wong C.H., Matai R., Morice A.H. Cough induced by low pH. Respir. Med. 1999; 93: 58-61.

24. Wong C.H., Morice A.H. Cough threshold in patients with chronic obstructive pulmonary disease. Thorax 1999; 54 : 62-64.

25. Morice A.H., Kastelik J.A., Thompson R. Cough challenge in the assessment of cough reflex. Br. J. Clin. Pharmacol. 2001; 52: 365-375.

26. Nejla S., Fujimura M., Kamio Y. Comparison between tidal breathing and dosimeter methods in assessing cough receptor sensitivity to capsaicin. Respirology 2000; 5: 337-342.

27. Barros M.J., Zammattio S.L., Rees P.J. Effect of changes in inspiratory flow rate on cough responses to inhaled capsaicin. Clin. Sci. (Lond.) 1991; 81: 539-542.

28. Barros M.J., Zammattio S.J., Rees P.J. Importance of inspiratory flow rate in the cough response to citric acid inhalation in normal subjects. Clin. Sci. (Lond) 1990; 78: 521-525.

29. O'Connell F., Thomas V.E., Studham J.M. et al. Capsaicin cough sensitivity increases during upper respiratory infection. Respir. Med. 1996; 90: 279-286.

30. Hansson L., Wollmer P., Dahlback M., Karlsson J.A. Regional sensitivity of human airways to capsaicininduced cough. Am. Rev. Respir. Dis. 1992; 145: 1191-1195.

31. Hutchings H.A., Morris S., Eccles R., Jawad M.S. Voluntary suppression of cough induced by inhalation of capsaicin in healthy volunteers. Respir. Med. 1993; 87: 379-382.

32. Prudon B, Vara D.D., Pavord I.D., Birring S.S. Analysis of cough reflex sensitivity data. Thorax 2005; 60 (suppl. II): ii107.

33. Prudon B., Birring S.S., Vara D.D. et al. Cough and glotticstop reflex sensitivity in health and disease. Chest 2005; 127: 550-557.

34. Crapo R.O., Casaburi R., Coates A.L. et al. Guidelines for methacholine and exercise challenge testing - 1999. Am. J. Respir. Crit. Care Med. 2000; 161: 309-329.

35. Morice A.H., Higgins K.S., Yeo W.W. Adaptation of cough reflex with different types of stimulation. Eur. Respir. J. 1992; 5: 841-847.

36. Schmidt D., Jorres R.A., Magnussen H. Citric acid-induced cough thresholds in normal subjects, patients with 
bronchial asthma, and smokers. Eur. J. Med. Res. 1997; 2 : 384-388.

37. Barber C.M., Curran A.D., Bradshaw L.M. et al. Reproducibility and validity of a Yan-style portable citric acid cough challenge. Pulm. Pharmacol. Ther. 2005; 18: $177-180$

38. Grattan T.J., Marshall A.E., Higgins K.S., Morice A.H. The effect of inhaled and oral dextromethorphan on citric acid induced cough in man. Br. J. Clin. Pharmacol. 1995; 39: 261-263.

39. Morice A.H., Marshall A.E., Higgins K.S., Grattan T.J. Effect of inhaled menthol on citric acid induced cough in normal subjects. Thorax 1994; 49: 1024-1026.

40. Rostami-Hodjegan A., Abdul-Manap R., Wright C.E. et al. The placebo response to citric acid-induced cough: pharmacodynamics and gender differences. Pulm. Pharmacol. Ther. 2001; 14: 315-319.

41. Wright C.E., Campbell R.J., Morice A.H. Citric acid inhalation cough challenge in chronic cough patients and controls using the KOKO Digidoser. Proc. Am. Thorac. Soc. 2006; 3: A372.

42. Fujimura M., Kamio Y., Sakamoto S. et al. Tachyphylaxis to capsaicin-induced cough and its reversal by indomethacin, in patients with the sinobronchial syndrome. Clin. Auton. Res. 1992; 2: 397-401.

43. Fujimura M., Sakamoto S., Kamio Y., Matsuda T. Effects of methacholine induced bronchoconstriction and procaterol induced bronchodilation on cough receptor sensitivity to inhaled capsaicin and tartaric acid. Thorax 1992; 47: 441-445.

44. Nieto L., de Diego A., Perpina M. et al. Cough reflex testing with inhaled capsaicin in the study of chronic cough. Respir. Med. 2003; 97: 393-400.

45. Wright C.E., Jackson J., Thompson R.H., Morice A.H. Validation of the citric acid cough challenge using the KOKO Digidoser system in healthy adult volunteers. Proc. Am. Thorac. Soc. 2007 (in press)

46. Dicpinigaitis P.V., Alva R.V. Safety of capsaicin cough challenge testing. Chest 2005; 128: 196-202.

47. O'Connell F., Thomas V.E., Pride N.B. Adaptation of cough reflex with different types of stimulation. Eur. Respir. J. 1992; 5: 1296-1297.

48. Dicpinigaitis P.V., Rauf K. The influence of gender on cough reflex sensitivity. Chest 1998; 113: 1319-1321.

49. Fujimura M., Kasahara K., Kamio Y. et al. Female gender as a determinant of cough threshold to inhaled capsaicin. Eur. Respir. J. 1996; 9: 1624-1626.

50. Thompson R., Wright C., Morice A.H. Female gender and enhanced citric acid induced cough response. Thorax 1999; 54 (suppl. 3): A75.

51. Fujimura M., Sakamoto S., Kamio Y., Matsuda T. Sex difference in the inhaled tartaric acid cough threshold in non-atopic healthy subjects. Thorax 1990; 45: 633-634.

52. International Society for the Study of Cough. Who are we? www.hull.ac.uk/ISSC/who_are_we.html. Date last updated: January 2007. Date last accessed: January 2007.

53. Mercer T.T. Production of therapeutic aerosols; principles and techniques. Chest 1981; 80 (suppl. 6): 813-818.

54. Sterk P.J., Plomp A., van de Vate J.F., Quanjer P.H. Physical properties of aerosols produced by several jet- and ultrasonic nebulizers. Bull. Eur. Physiopathol. Respir. 1984; 20: 65-72.

55. Eschenbacher W.L., Boushey H.A., Sheppard D. Alteration in osmolarity of inhaled aerosols cause bronchoconstriction and cough, but absence of a permeant anion causes cough alone. Am. Rev. Respir. Dis. 1984; 129: 211-215.
56. Lavorini F., Fontana G.A., Pantaleo T. et al. Fog-induced respiratory responses are attenuated by nedocromil sodium in humans. Am. J. Respir. Crit. Care Med. 2001; 163: $1117-1120$

57. Fontana G.A., Pantaleo T., Lavorini F. et al. A noninvasive electromyographic study on threshold and intensity of cough in humans. Eur. Respir. J. 1997; 10: 983-989.

58. Fontana G.A., Pantaleo T., Lavorini F. et al. Defective motor control of coughing in Parkinson's disease. Am. J. Respir. Crit. Care Med. 1998; 158: 458-464.

59. Higenbottam T., Jackson M., Woolman P. et al. The cough response to ultrasonically nebulized distilled water in heart-lung transplantation patients. Am. Rev. Respir. Dis. 1989; 140: 58-61.

60. Morice A.H., Turley A.J., Linton K. Human ACE gene polymorphism and distilled water induced cough. Thorax 1997; 52: 111-113.

61. Lowry R., Higenbottam T., Johnson T., Godden D. Inhibition of artificially induced cough in man by bronchodilators. Br. J. Clin. Pharmacol. 1987; 24: 503-510.

62. Lowry R., Wood A., Johnson T., Higenbottam T. Antitussive properties of inhaled bronchodilators on induced cough. Chest 1988; 93: 1186-1189.

63. Ventresca P.G., Nichol G.M., Barnes P.J., Chung K.F. Inhaled furosemide inhibits cough induced by low chloride content solutions but not by capsaicin. Am. Rev. Respir. Dis 1990; 142: 143-146.

64. Fontana G.A., Pantaleo T., Lavorini F. et al. Coughing in laryngectomized patients. Am. J. Respir. Crit. Care Med. 1999; 160: 1578-1584.

65. Tanaka $S$., Hirata K., Kurihara $N$. et al. Effect of loratadine, an $\mathrm{H}_{1}$ antihistamine, on induced cough in non-asthmatic patients with chronic cough. Thorax 1996; 51: 810-814.

66. Fontana G.A., Pantaleo T., Lavorini F. et al. Repeatability of cough-related variables during fog challenges at threshold and suprathreshold stimulus intensity in humans. Eur. Respir. J. 1999; 13: 1447-1450.

67. Woolf C.R., Rosenberg A. Objective assessment of cough suppressants under clinical conditions using a tape recorder system. Thorax 1964; 19: 125-130.

68. Loudon R.G., Brown L.C. Cough frequency in patients with respiratory disease. Am. Rev. Respir. Dis. 1967; 96: $1137-1143$

69. Loudon R.G., Spohn S.K. Cough frequency and infectivity in patients with pulmonary tuberculosis. Am. Rev. Respir. Dis. 1969; 99: 109-111.

70. Archer L.N.J., Simpson H. Night cough counts and diary card scores in asthma. Arch. Dis. Child. 1985; 60: 473-474.

71. Hiew Y., Smith J.A., Cheetham B.M.G. et al. Automatic cough detection using digital signal processing techniques - the Manchester Cough Algorithm. Am. J. Respir. Crit. Care Med. 2002; 165: A832.

72. Birring S.S., Matos S., Patel R.B. et al. The relationship between cough counts and quality of life in patients with chronic cough. Eur. Respir. J. 2004; 24: Suppl. 48, 47s.

73. Barry S.J., Dane A.D., Morice A.H., Walmsley A.D. The automatic recognition and counting of cough. Cough 2006; $2: 8$.

74. Bennett F.M., Irwin R.S., Brown L., French C.L. Automatic recognition of coughs. Am. Rev. Respir. Dis. 1991; 143: A666.

75. Hsu J.Y., Stone R.A., Logan-Sinclair R.B. et al. Coughing frequency in patients with persistent cough: assessment 
using a 24 hour ambulatory recorder. Eur. Respir. J. 1994; 7: $1246-1253$.

76. Chang A.B., Newman R.G., Phelan P.D., Robertson C.F. A new use for an old Holter monitor: an ambulatory cough meter. Eur. Respir. J. 1997; 10: 1637-1639.

77. Subburaj S., Hirtum A.V., Quanten S., Berckmans D. An algorithm to automatically identify cough sounds from clinical recordings. Eur. Respir. J. 2003; 22 (suppl. 45): 172s.

78. Smith J.A., Cheetham B.M.G., Earis J.E., Woodcock A.A. Cough seconds: a new measure of cough. Am. J. Respir. Crit. Care Med. 2006; 165: A832.

79. Coyle M.A., Keenan B.D., Mayleben D.W. et al. Objective assessment of cough over a 24-hr period in patients with COPD. Am. J. Respir. Crit. Care Med. 2004; 169: A606.

80. Smith J., Owen E., Earis J., Woodcock A. Effect of codeine on objective measurement of cough in chronic obstructive pulmonary disease. J. Allergy Clin. Immunol. 2006; 117: 831-835.

81. Smith J.A., Owen E.C., Jones A.M. et al. Objective measurement of cough during pulmonary exacerbations in adults with cystic fibrosis. Thorax 2006; 61: 425-429.

82. Birring S.S., Matos S., Patel R.B. et al. Cough frequency, cough sensitivity and health status in patients with chronic cough. Respir. Med. 2006; 100: 1105-1109.

83. Matos S., Birring S.S., Pavord I.D., Evans D.H. Detection of cough signals in continuous audio recordings using hidden Markov models. IEEE Trans Biomed Eng. 2006; 53: 1078-1083.

84. Korpas J., Sadlonova J., Salat D., Masarova E. The origin of cough sounds. Bull. Eur. Physiopathol. Respir. 1987; 23 (suppl. 10): $47 \mathrm{~s}-50 \mathrm{~s}$.

85. Hamutcu R., Francis J., Karakoc F., Bush A. Objective monitoring of cough in children with cystic fibrosis. Pediatr. Pulmonol. 2002; 34: 331-335.

86. Thorpe C.W., Toop L.J., Dawson K.P. Towards a quantitative description of asthmatic cough sounds. Eur. Respir. J. 1992; 5: 685-692.

87. Olia P.M., Sestini P., Vagliasindi M. Acoustic parameters of voluntary cough in healthy non-smoking subjects. Respirology 2000; 5: 271-275.

88. Corrigan D.L., Paton J.Y. Pilot study of objective cough monitoring in infants. Pediatr. Pulmonol. 2003; 35: $350-357$

89. Smith J.A., Earis A., Woodcock A.A., Earis J.E. Acoustic properties of spontaneous coughs in common respiratory diseases. Am. J. Respir. Crit. Care Med. 2004; 169: A200.

90. Bland J.M., Altman D.G. Comparing methods of measurement: why plotting difference against standard method is misleading. Lancet 1995; 346: 1085-1087.

91. World Health Organization. Preamble to the Constitution of the World Health Organization as adopted by the International Health Conference, New York, 19 June - 22 July 1946; signed on 22 July 1946 by the representatives of 61 States. (Official records of the World Health Organization, no. 2, p. 100) and entered into force on 7 April 1948

92. French C.L., Irwin R.S., Curley F.J., Krikorian C.J. Impact of chronic cough on quality of life. Arch. Intern. Med. 1998; 158: 1657-1661.

93. Gulsvik A., Refvem O.K. A scoring system on respiratory symptoms. Eur. Respir. J. 1988; 1: 428-432.

94. Chang A.B., Newman R.G., Carlin J.B. et al. Subjective scoring of cough in children: parent-completed $v s$ childcompleted diary cards $v s$ an objective method. Eur. Respir. J. 1998; 11: 462-466.
95. Ellul-Micallef $R$. Effect of terbutaline sulphate in chronic "allergic" cough. Br. Med. J. (Clin. Res. Ed.) 1983; 287: 940-943.

96. Faniran A.O., Peat J.K., Woolcock A.J. Measuring persistent cough in children in epidemiological studies: development of a questionnaire and assessment of prevalence in two countries. Chest 1999; 115: 434-439.

97. Brunekreef B., Groot B., Rijcken B. et al. Reproducibility of childhood respiratory symptom questions. Eur. Respir. J. 1992; 5: 930-935.

98. Birring S.S., Brightling C.E., Symon F.A. et al. Idiopathic chronic cough: association with organ specific autoimmune disease and bronchoalveolar lymphocytosis. Thorax 2003; 58: 1066-1070.

99. Brightling C.E., Monterio W., Green R.H. et al. Induced sputum and other outcome measures in chronic obstructive pulmonary disease: safety and repeatability. Respir. Med. 2001; 95: 999-1002.

100. Birring S.S., Passant C., Patel R.B. et al. Chronic tonsillar enlargement and cough: preliminary evidence of a novel and treatable cause of chronic cough. Eur. Respir. J. 2004; 23: 199-201.

101. Brightling C.E., Ward R., Wardlaw A.J., Pavord I.D. Airway inflammation, airway responsiveness and cough before and after inhaled budesonide in patients with eosinophilic bronchitis. Eur. Respir. J. 2000; 15: 682-686.

102. Fayers P.M., Machin D. Quality of life: assessment, analysis and interpretation. 1st edn. Chichester: John Wiley \& Sons; 2000.

103. Juniper E.F. Health-related quality of life. In: Barnes P.J., Grunstein M.M., Leff A.R., Woodcock A.J., eds. Asthma. Philadelphia: Lippincott-Raven; 1997. 1487-1497.

104. Baiardini I., Braido F., Fassio O. et al. A new tool to assess and monitor the burden of chronic cough on quality of life: Chronic Cough Impact Questionnaire. Allergy 2005; 60: 482-488.

105. Birring S.S., Patel R.B., Carr A.J. et al. Assessment of quality of life in acute cough with the Leicester Cough Questionnaire (LCQ). Am. J. Respir. Crit. Care Med. 2004; 169: A509.

106. Raj A.A., Pavord I.D., Birring S.S. What is the minimal important difference of the Leicester Cough Questionnaire? Thorax 2006; 21 (suppl. 2): 109.

107. Morice A.H., Menon M.S., Mulrennan S.A. et al. Opiate therapy in chronic cough. Am. J. Respir. Crit. Care Med. 2007; 175: 312-315.

108. French C.T., Fletcher K.E., Irwin R.S. A comparison of gender differences in health-related quality of life in acute and chronic coughers. Chest 2005; 127: 1991-1998.

109. French C.T., Fletcher K.E., Irwin R.S. Gender differences in health-related quality of life in patients complaining of chronic cough. Chest 2004; 125: 482-488.

110. Birring S.S., Patel R.B., Prudon B. et al. Quality of life in chronic cough. Am. J. Respir. Crit. Care Med. 2003; 167: A135.

111. Dicpinigaitis P.V., Tso R., Banauch G.I. Prevalence of depressive symptoms among patients with chronic cough. Chest 2006; 130: 1839-1843.

112. Kalpaklioglu A.F., Kara T., Kurtipek E. et al. Evaluation and impact of chronic cough: comparison of specific vs generic quality-of-life questionnaires. Ann Allergy Asthma Immunol. 2005; 94: 581-585.

113. Choudry N.B., Fuller R.W. Sensitivity of the cough reflex in patients with chronic cough. Eur. Respir. J. 1992; 5: 296-300. 
114. Schroeder K., Fahey T. Systematic review of randomized controlled trials of over the counter cough medicines for acute cough in adults. Br. Med. J. 2002; 324: 1-6.

115. Karlsson J.A., Fuller R.W. Pharmacological regulation of the cough reflex - from experimental models to antitussive effects in man. Pulm. Pharmacol. Ther. 1999; 12: 215-228.

116. Moreaux B., Beerens D., Gustin P. Development of a cough induction test in pigs: effects of SR 48968 and enalapril. J. Vet. Pharmacol. Ther. 1999; 22: 387-389.

117. Kamei J., Hukuhara T., Kasuya Y. Dopaminergic control of the cough reflex as demonstrated by the effects of apomorphine. Eur. J. Pharmacol. 1987; 141: 511-513.

118. Korpas $J$. Differentiation of the expiration and the cough reflex. Physiol. Bohemoslov. 1972; 21: 677-680.

119. Karlsson J.A., Sant'Ambrogio G., Widdicombe J. Afferent neural pathways in cough and reflex bronchoconstriction. J. Appl. Physiol. 1988; 65: 1007-1023.

120. Forsberg K., Karlsson J.A., Theodorsson E. et al. Cough and bronchoconstriction mediated by capsaicin-sensitive sensory neurons in the guinea-pig. Pulm. Pharmacol. 1988; 1: $33-39$.

121. Fox A.J., Barnes P.J., Urban L., Dray A. An in vitro study of the properties of single vagal afferents innervating guinea-pig airways. J. Physiol. (Lond.) 1993; 469: 21-35.

122. Undem B.J., Carr M.J., Kollarik M. Physiology and plasticity of putative cough fibres in the Guinea pig. Pulm. Pharmacol. Ther. 2002; 15: 193-198.

123. Fox A.J. Modulation of cough and airway sensory fibres. Pulm. Pharmacol. 1996; 9: 335-342.

124. Fox A.J., Lalloo U.G., Belvisi M.G. et al. Bradykininevoked sensitization of airway sensory nerves: a mechanism for ACE-inhibitor cough. Nat. Med. 1996; 2: 814-817.

125. Fox A.J., Barnes P.J., Venkatesan P., Belvisi M.G. Activation of large conductance potassium channels inhibits the afferent and efferent function of airway sensory nerves in the guinea pig. J. Clin. Invest 1997; 99: 513-519.

126. Tatar M., Pecova R., Karcolova D. Sensitivity of the cough reflex in awake guinea pigs, rats and rabbits. Bratisl. Lek. Listy 1997; 98: 539-543.

127. Lalloo U.G., Fox A.J., Belvisi M.G. et al. Capsazepine inhibits cough induced by capsaicin and citric acid but not by hypertonic saline in guinea pigs. J. Appl. Physiol. 1995; 79: $1082-1087$.

128. Hay D.W., Giardina G.A., Griswold D.E. et al. Nonpeptide tachykinin receptor antagonists. III. SB 235375, a low central nervous system-penetrant, potent and selective neurokinin-3 receptor antagonist, inhibits citric acidinduced cough and airways hyper-reactivity in guinea pigs. J. Pharmacol. Exp. Ther. 2002; 300: 314-323.

129. Emonds-Alt X., Advenier C., Cognon C. et al. Biochemical and pharmacological activities of SR 144190, a new potent non-peptide tachykinin $\mathrm{NK}_{2}$ receptor antagonist. Neuropeptides 1997; 31: 449-458.

130. Belvisi M.G., Venkatesan P., Barnes P.J., Fox A.J. A comparison of the chemosensitivity of the isolated guinea pig and human vagus nerves. Am. J. Respir. Crit. Care Med. 1998; 157: A487.

131. Canning B.J., Mazzone S.B., Meeker S.N. et al. Identification of the tracheal and laryngeal afferent neurones mediating cough in anaesthetized guinea-pigs. J. Physiol. (Lond.) 2004; 557: 543-558.

132. Mazzone S.B., Mori N., Canning B.J. Synergistic interactions between airway afferent nerve subtypes regulating the cough reflex in guinea-pigs. J. Physiol. (Lond.) 2005; 569: 559-573.

133. Bolser D.C., Hey J.A., Chapman R.W. Influence of central antitussive drugs on the cough motor pattern. J. Appl. Physiol. 1999; 86: 1017-1024.

134. Bolser D.C., Mcleod R.L., Tulshian D.B., Hey J.A. Antitussive action of nociceptin in the cat. Eur. J. Pharmacol 2001; 430: 107-111.

135. Bolser D.C., Aziz S.M., DeGennaro F.C. et al. Antitussive effects of GABAB agonists in the cat and guinea-pig. Br. J. Pharmacol. 1993; 110: 491-495.

136. Tatar M., Pecova R. Laryngeal and tracheobronchial cough in anaesthetized cats and guinea-pigs. Stud. Pneumol. Phtiseol. 1994; 54: 143-145.

137. Plevkova J., Kollarik M., Brozmanova M. et al. Modulation of experimentally induced cough by stimulation of nasal mucosa in cats and guinea pigs. Respir. Physiol. Neurobiol. 2004; 142: 225-235.

138. Tatar M., Karcolova D., Pecova R. et al. Experimental modulation of the cough reflex. Eur. Respir. Rev. 2002; 12: 264-269.

139. Widdicombe J. Sensory mechanisms. Pulm. Pharmacol. 1996; 9: 383-387.

140. Moreaux B., Nemmar A., Beerens D., Gustin P. Inhibiting effect of ammonia on citric acid-induced cough in pigs: a possible involvement of substance P. Pharmacol. and Toxicol. 2000; 87: 279-285.

141. Xiang A., Uchida Y., Nomura A. et al. Effects of airway inflammation on cough response in the guinea pig. J. Appl. Physiol. 1998; 85: 1847-1854.

142. Liu Q., Fujimura M., Tachibana H. et al. Characterization of increased cough sensitivity after antigen challenge in guinea pigs. Clin. Exp. Allergy 2001; 31: 474-484.

143. House A., Celly C., Skeans $S$. et al. Cough reflex in allergic dogs. Eur. J. Pharmacol. 2004; 492: 251-258.

144. Hirata R., Nabe T., Kohno S. Augmentation of spontaneous cough by enalapril through up-regulation of bradykinin B1 receptors in guinea pigs. Eur. J. Pharmacol 2003; 474: 255-260.

145. Ito K., Ito K., Sawada Y. et al. Toxicodynamic analysis of cough and inflammatory reactions by angiotensin-converting enzyme inhibitors in guinea pig. J. Pharmacol. Exp. Ther. 1995; 275: 920-925.

146. Bergren D.R. Chronic tobacco smoke exposure increases cough to capsaicin in awake guinea pigs. Respir. Physiol. 2001; 126: 127-140.

147. Joad J.P., Munch P.A., Bric J.M. et al. Passive smoke effects on cough and airways in young guinea pigs: role of brainstem substance P. Am. J. Respir. Crit. Care Med. 2004; 169: 499-504.

148. Karlsson J.A., Zackrisson C., Lundberg J.M. Hyperresponsiveness to tussive stimuli in cigarette smoke-exposed guinea-pigs: a role for capsaicin-sensitive, calcitonin generelated peptide-containing nerves. Acta. Physiol. Scand. 1991; 141: 445-454.

149. Myers A.C., Kajekar R., Undem B.J. Allergic inflammation-induced neuropeptide production in rapidly adapting afferent nerves in guinea pig airways. Am. J. Physiol. Lung Cell Mol. Physiol. 2002; 282: L775-L781.

150. Hunter D.D., Myers A.C., Undem B.J. Nerve growth factorinduced phenotypic switch in guinea pig airway sensory neurons. Am. J. Respir. Crit. Care Med. 2000; 161: $1985-1990$

151. Riccio M.M., Myers A.C., Undem B.J. Immunomodulation of afferent neurons in guinea-pig isolated airway. J. Physiol. (Lond.) 1996; 491: 499-509. 
152. Advenier $C$. Tachykinin $\mathrm{NK}_{2}$ receptors further characterized in the lung with nonpeptide receptor antagonists. Can. J. Physiol. Pharmacol. 1995; 73: 878-884.

153. Dicpinigaitis P.V., Dobkin J.B., Reichel J. Antitussive effect of the leukotriene receptor antagonist zafirlukast in subjects with cough-variant asthma. J. Asthma 2002; 39: 291-297.

154. O'Connell F., Thomas V.E., Pride N.B., Fuller R.W. Capsaicin cough sensitivity decreases with successful treatment of chronic cough. Am. J. Respir. Crit. Care Med. 1994; 150: 374-380.

155. Groneberg D.A., Niimi A., Dinh Q.T. et al. Increased expression of transient receptor potential vanilloid-1 in airway nerves of chronic cough. Am. J. Respir. Crit. Care Med. 2004; 170: 1276-1280.

156. Mitchell J.E., Campbell A.P., New N.E. et al. Expression and characterization of the intracellular vanilloid receptor $\left(\mathrm{TRPV}_{1}\right)$ in bronchi from patients with chronic cough. Exp. Lung Res. 2005; 31: 295-306.

157. Undem B.J., Chuaychoo B., Lee M.G. et al. Subtypes of vagal afferent Cfibres in guinea-pig lungs. J. Physiol. (Lond.) 2004; 556: 905-917.

158. Dicpinigaitis P.V., Dobkin J.B. Effect of zafirlukast on cough reflex sensitivity in asthmatics. J. Asthma 1999; 36: 265-270.

159. Brightling C.E., Bradding P., Symon F.A. et al. Mast cell infiltration of airway smooth muscle in asthma. N. Engl. J. Med. 2002; 346: 1699-1705.

160. Manap R.A., Wright C.E., Gregory A. et al. The antitussive effect of dextromethorphan in relation to CYP2D6 activity. Br. J. Clin. Pharmacol. 1999; 48: 382-387.
161. Coulter D.M., Edwards I.R. Cough associated with captopril and enalapril. Br. Med. J. (Clin. Res. Ed.) 1987; 294: $1521-1523$

162. Mulrennan S., Wright C., Thompson R. et al. Effect of salbutamol on smoking related cough. Pulm. Pharmacol. Ther. 2004; 17: 127-131.

163. Dicpinigaitis P.V. Cough reflex sensitivity in cigarette smokers. Chest 2003; 123: 685-688.

164. Tomlinson J.E., McMahon A.D., Chaudhuri R. et al. Efficacy of low and high dose inhaled corticosteroid in smokers versus non-smokers with mild asthma. Thorax 2005; 60: 282-287.

165. Eccles R., Morris S., Jawad M. Lack of effect of codeine in the treatment of cough associated with acute upper respiratory tract infection. J. Clin. Pharmacol. Ther. 1992; 17: 175-180.

166. Eccles R. The powerful placebo in cough studies? Pulm. Pharmacol. Ther. 2002; 15: 303-308.

167. Pavesi L., Subburaj S., Porter-Shaw K. Application and validation of a computerized cough acquisition system for objective monitoring of acute cough: a meta-analysis. Chest 2002; 120: 1121-1128.

168. Morice A.H., Kastelik J.A. Cough. 1: Chronic cough in adults. Thorax 2003; 58: 901-907.

169. Kiljander T.O., Salomaa E.R., Hietanen E.K. et al. Gastroesophageal reflux and bronchial responsiveness: correlation and the effect of fundoplication. Respiration 2002; 69: 434-439.

170. Harding S.M. Recent clinical investigations examining the association of asthma and gastroesophageal reflux. Am. J. Med. 2003; 115 (suppl. 3A): 39S-44S.

Поступила 21.10.08

удК 616.24-008.41-07 